\title{
GEMINI-E3, a general equilibrium model of international-national interactions between economy, energy and the environment
}

\author{
Alain Bernard · Marc Vielle
}

Published online: 28 February 2007

(C) Springer-Verlag 2007

\begin{abstract}
The purpose of this paper is to present the new version of GEMINI-E3, which is the fifth and incorporates significant changes from the previous version in particular with respect to its size and its modularity. GEMINI-E3 is a Computable General Equilibrium Model and represents now a family of models of different specifications and with several successive versions. It retains many specifications that are common to CGE models but also some specific features, mainly concerning the measurement and analysis of the welfare cost of policies and the great detail in the representation of taxation and social security contributions. The paper gives a detailed presentation of the model, its main blocks and equations, and shows how it can be adapted to specific contexts. In particular a new version is being developed jointly with the standard one, taking into account the constraints of the European Monetary Union and the unbalances in the labor markets of industrialized countries (GEMINI-EMU). This clearly shows that CGE models, beside their main virtue that is total consistency at the domestic and at the world levels, are very flexible in their specification.
\end{abstract}

\section{Introduction}

GEMINI-E3 is the name of the first Computable General Equilibrium Model developed jointly by the French Ministry of Equipment and the French Atomic

\footnotetext{
A. Bernard

Ministry of Equipment, Transport, and Housing, Paris, France e-mail: alain.bernard@equipement.gouv.fr

M. Vielle ( $\bowtie)$

REME-EPFL, Ecole Polytechnique Fédérale de Lausanne, Lausanne, Switzerland e-mail: mvielle@cict.fr
} 
Energy Agency. The team now benefits from a nearly 15 years experience in CGE modeling, associated with a close collaboration with the main research teams working in the field of climate change policy and with a participation to the political debate on this topic. The new version, which is the fifth, has been developed with the collaboration of the Swiss Federal Institute of Technology (Lausanne). GEMINI-E3 is presently a family of general equilibrium models, all of them multi-sector and dynamic, but some multi-country and some purely domestic or aimed at domestic policy assessment purposes. ${ }^{1}$ The original version of the multi-country model is fully described in Bernard and Vielle (1998). Several successive versions have been developed, with an increasing number of countries/regions (from 3 to 28) and an increasing number of sectors (from 8 to 18). A more detailed representation of countries and sectors was required by new types of appraisal, from very global ones such as the Kyoto Protocol to more precise ones such as the European Trading System implemented from the start of 2005. More precisely, the main and successive uses of the model have been directed toward:

- analyzing the implementation of economic instruments for greenhouse gases (GHG) emissions in a second-best setting (Bernard and Vielle 2000b);

- assessing the strategic allocation of greenhouse gases emission allowances in the EU-wide market (Bernard et al. 2005b);

- assessing and comparing regional welfare costs associated with alternative multi-gas strategies for a stabilization of global greenhouse gases emissions in the long run (Bernard et al. 2006);

- analyzing the behavior of Russia in the Kyoto Protocol (Bernard et al. 2003);

- assessing the economic impact of the US withdrawal from the Kyoto Protocol (Bernard and Vielle 2002);

- analyzing the French Climate policy formulated under the Kyoto Protocol (Bernard and Vielle 1999a,b);

- assessing the economic impact of a French nuclear moratorium with respect to the Kyoto Protocol (Bernard and Vielle 2000a);

- assessing the cost of the Kyoto Protocol for Switzerland with and without international emissions trading (Bernard et al. 2005a);

- assessing the double dividend hypothesis of climate change policy, with due consideration to preexisting tax distortions in factor markets for the Swiss economy (Bernard et al. 2004);

- assessing the effects of the increase of oil prices on global and regional GHG emissions (Vielle and Viguier 2007).

A clearer focus put on European climate change policies raised the question of the representation of the European Monetary Union, linking most of the members of the European Union, and of the way of taking into account the constraints of the single currency and the spill-over effects of domestic policies. Effectively, as long as the policies were roughly similar among European

1 GEMINI-E3 France (Bernard and Vielle 1999a,b), GEMINI-E3 Switzerland (Bernard et al. 2005a), GEMINI-E3 Tunisia (Bernard et al. 2006a). 
countries, which means that they also responded in a similar way, there was no need to take explicitly into account the mechanisms of the monetary union. This is not anymore the case when purely domestic policies or significantly differing policies are contemplated. This is the reason why a new version of the model, GEMINI-EMU, has been developed along these lines. The two versions have most in common and the following technical description, specific to GEMINI-E3, is also largely valid for GEMINI-EMU. Differences between the two models will be presented in Sect. 5: though they may appear very limited, they have sweeping effects on policy implementation and efficiency.

As for numerical specification and resolution, the present version of GEMINI-E3 (and GEMINI-EMU) is formulated as a mixed complementarity problem using GAMS with the PATH solver (Ferris and Munson 2000; Ferris and Pang 1997).

\section{Structure of the model}

As most CGE models, GEMINI-E3 simulates all relevant markets, domestic and international, considered as perfectly competitive, which implies that the corresponding prices are flexible: markets for commodities (through relative prices), for labor (through wages), for domestic and international savings (through rates of interest and exchange rates ${ }^{2}$ ). Time periods are linked in the model through endogenous real rates of interest determined through the balancing of savings and investment. National and regional models are linked by endogenous real exchange rates resulting from constraints on foreign trade deficits or surpluses. There is one notable-and usual-exception to this general assumption of perfect competition, which concerns foreign trade. Goods of the same sector produced by the different countries are not supposed to be perfectly competitive. They are considered as economically different goods, more or less substitutable according to an elasticity of substitution known as Armington's (Armington assumption 1969). A high value means a high degree of competition in the world market, a low value a small degree of competition. This assumption is justified by the high level of aggregation in the nomenclature of goods: agricultural production in developed countries has little in common with agricultural production in developing countries, and significant differences also exist among developed countries and among developing countries. It is also inescapable because, without this assumption, the countries would specialize, each in one sector or a very limited number of sectors. ${ }^{3}$ This treatment of

\footnotetext{
2 The real exchange rate between two countries is the relative price of the numéraires chosen in each country (and usually based on a basket of goods representative of GDP). Technically, exchange rates for all countries/regions are expressed relatively to a reference one, taken here as AFR (rest of Africa).

3 This is a side-effect of the general assumption of constant returns to scale in production (with the exception of agriculture and fossil fuels).
} 
foreign trade will be detailed further below. Compared to other CGE models, GEMINI-E3 has two main specificities:

- a comprehensive and detailed representation of indirect taxation. Indirect taxation and social contributions rates are differentiated by commodity (taxes on production, on imports), by sector (social contributions, subsidies), by sector $\times$ commodity (intermediate consumption), by commodity $\times$ institutional sector (final demand), and by commodity $\times$ sector $\times$ IS (investment);

- the focus put on the measurement of the welfare cost of policies, and its analysis by main components, either domestic or international ("imported"). Methodology of welfare measurement will be detailed in Sect. 4.

Time periods are linked in the model through endogenous real rates of interest determined by equilibrium between savings and investment. National and regional models are linked by endogenous real exchange rates resulting from constraints on foreign trade deficits or surpluses.

Table 1 gives an overall description and the main characteristics of the model. The main outputs of the GEMINI-E3 model are by country and annually: carbon taxes, marginal abatement costs and prices of tradable permits (when relevant), effective abatement of $\mathrm{CO}_{2}$ emissions, net sales of tradable permits (when relevant), total net welfare loss and components (net loss from terms of trade, pure deadweight loss of taxation, net purchases of tradable permits when relevant), macro-economic aggregates (e.g. production, imports and final demand), real exchange rates and real interest rates, and data at the industrylevel (e.g. change in production and in factors of production, prices of goods).

The nomenclature that has been chosen allows to individualize the main economic countries/regions and GHG emitters. Table 2 gives for the countries and the regions represented in the model their shares in the world population and the world GDP, and in the global GHG emissions. Except the two biggest economies (US and Japan) and the two highest emitters (US and China), no country or region has a bigger than $10 \%$ share either in the world economy or in the GHG emissions.

\subsection{Total demand}

For each sector the model computes total demand $\left(Y_{i r}\right)$ as the sum of final demand (investment $\left(I V_{i r}\right)$, consumption $\left(H C_{i r}\right.$ and $\left.G C_{i r}\right)$, exports $\left.\left(E X_{i r}\right)\right)$ and intermediate consumption by all sectors $\left(I C_{i k r}\right)$ :

$$
Y_{i r}=H C_{i r}+G C_{i r}+E X_{i r}+I V_{i r}+\sum_{k} I C_{i k r}
$$

where $i, r$, and $k$ stand for sector, region, and product respectively. 
Table 1 Dimensions of the GEMINI-E3 model

\begin{tabular}{|c|c|c|}
\hline \multicolumn{2}{|l|}{ Countries or regions } & \multirow{2}{*}{$\begin{array}{l}\text { Sectors } \\
\text { Energy }\end{array}$} \\
\hline Annex B & & \\
\hline Germany & DEU & 01 Coal \\
\hline France & FRA & 02 Crude oil \\
\hline United Kingdom & GBR & 03 Natural gas \\
\hline Italy & ITA & 04 Refined petroleum \\
\hline Spain & ESP & 05 Electricity \\
\hline Netherlands & NLD & Non-energy \\
\hline Belgium & BEL & 06 Agriculture \\
\hline Poland & POL & 07 Forestry \\
\hline Rest of EU-25 & OEU & 08 Mineral products \\
\hline Switzerland & CHE & 09 Chemical rubber plastic \\
\hline Other European Countries & XEU & 10 Metal and metal products \\
\hline United States of America & USA & 11 Paper products publishing \\
\hline Canada & CAN & 12 Transport n.e.c. \\
\hline Australia and New Zealand & AUZ & 13 Sea transport \\
\hline Japan & JAP & 14 Air transport \\
\hline Russia & RUS & 15 Consuming goods \\
\hline Rest of Former Soviet Union & XSU & 16 Equipment goods \\
\hline Non-annex B & & 17 Services \\
\hline China & $\mathrm{CHI}$ & 18 Dwellings \\
\hline Brazil & BRA & \\
\hline India & IND & Household sector \\
\hline Mexico & MEX & \\
\hline Venezuela & VEN & Primary factors \\
\hline Rest of Latin America & LAT & Labor \\
\hline Turkey & TUR & Capital \\
\hline Rest of Asia & ASI & Energy \\
\hline Middle East & MID & Fixed factor (sector 01-03) \\
\hline Tunisia & TUN & Other inputs \\
\hline Rest of Africa & AFR & \\
\hline
\end{tabular}

\subsection{Imports}

Imports $\left(M_{i r}\right)$ are computed from total demand according to the Armington assumption (1969):

$$
M_{i r}=Y_{i r} \cdot \lambda_{i r}^{x} \cdot\left(1-\alpha_{i r}^{x}\right) \cdot\left[\frac{P Y_{i r}}{\lambda_{i r}^{x} \cdot P I_{i r} \cdot\left(1+\kappa_{i r}^{i}\right)}\right]^{\sigma_{i r}^{x}}
$$

where $\sigma_{i r}^{x}, \alpha_{i r}^{x}$ and $\lambda_{i r}^{x}$ represent the CES parameters, respectively the elasticity of substitution, the share parameter and the technology shifter and $P Y_{i r}$ the price of composite good, $P I_{i r}$ the price of import and $\kappa_{i r}^{i}$ the duty rate.

Imports are computed by origins $\left(M R_{i r h}\right)$ with an another CES function:

$$
M R_{i r h}=M_{i r} \cdot \lambda_{i r}^{i} \cdot \alpha_{i r h}^{i} \cdot\left[\frac{P I_{i r}}{\lambda_{i r}^{i} \cdot P X_{i h} \cdot\left(e_{h} / e_{r}\right)}\right]^{\sigma_{i r}^{a i}}
$$

where $e_{h}$ is the exchange rate and $P X_{i h}$ the price of exports. 
Table 2 Countries and regions represented in GEMINI-E3 - structural data in 2001

\begin{tabular}{|c|c|c|c|c|c|c|}
\hline $\begin{array}{l}\text { Countries } \\
\text { or regions }\end{array}$ & Population $^{\mathrm{a}}$ & $\begin{array}{l}\text { GHG } \\
\text { emissions }^{b}\end{array}$ & $\mathrm{GDP}^{\mathrm{c}}$ & \% Pop. & $\% \mathrm{GHG}$ & $\%$ GDP \\
\hline DEU & 82.3 & 310 & 1,889 & 1.4 & 3.2 & 6.0 \\
\hline FRA & 59.3 & 160 & 1,347 & 1.0 & 1.6 & 4.3 \\
\hline GBR & 58.7 & 205 & 1,427 & 1.0 & 2.1 & 4.5 \\
\hline ITA & 57.7 & 157 & 1,113 & 1.0 & 1.6 & 3.5 \\
\hline ESP & 40.7 & 107 & 583 & 0.7 & 1.1 & 1.9 \\
\hline NLD & 15.9 & 105 & 400 & 0.3 & 1.1 & 1.3 \\
\hline BEL & 10.3 & 54 & 240 & 0.2 & 0.6 & 0.8 \\
\hline POL & 38.6 & 102 & 178 & 0.6 & 1.0 & 0.6 \\
\hline OEU & 88.4 & 250 & 1,190 & 1.5 & 2.6 & 3.8 \\
\hline $\mathrm{CHE}$ & 7.2 & 15 & 236 & 0.1 & 0.2 & 0.8 \\
\hline USA & 284.2 & 1,938 & 10,335 & 4.7 & 19.9 & 32.8 \\
\hline JAP & 127.0 & 376 & 4,159 & 2.1 & 3.9 & 13.2 \\
\hline XEU & 55.8 & 130 & 326 & 0.9 & 1.3 & 1.0 \\
\hline CAN & 30.7 & 479 & 711 & 0.5 & 4.9 & 2.3 \\
\hline AUZ & 22.9 & 186 & 417 & 0.4 & 1.9 & 1.3 \\
\hline TUR & 68.2 & 90 & 153 & 1.1 & 0.9 & 0.5 \\
\hline RUS & 146.6 & 489 & 300 & 2.4 & 5.0 & 1.0 \\
\hline XSU & 120.6 & 327 & 106 & 2.0 & 3.4 & 0.3 \\
\hline $\mathrm{CHI}$ & $1,274.0$ & 1,278 & 1,293 & 21.0 & 13.1 & 4.1 \\
\hline IND & $1,021.1$ & 429 & 463 & 16.8 & 4.4 & 1.5 \\
\hline ASI & 957.5 & 793 & 1,473 & 15.8 & 8.1 & 4.7 \\
\hline BRA & 173.9 & 244 & 497 & 2.9 & 2.5 & 1.6 \\
\hline VEN & 24.4 & 94 & 128 & 0.4 & 1.0 & 0.4 \\
\hline LAT & 224.6 & 322 & 735 & 3.7 & 3.3 & 2.3 \\
\hline MEX & 100.1 & 170 & 611 & 1.6 & 1.7 & 1.9 \\
\hline MID & 167.9 & 347 & 636 & 2.8 & 3.6 & 2.0 \\
\hline TUN & 9.6 & 34 & 20 & 0.2 & 0.3 & 0.1 \\
\hline AFR & 802.9 & 550 & 520 & 13.2 & 5.6 & 1.7 \\
\hline World & $6,071.0$ & 9,742 & 31,488 & 100.0 & 100.0 & 100.0 \\
\hline
\end{tabular}

\footnotetext{
${ }^{a}$ Million of inhabitants

$\mathrm{b}$ Million tonnes of carbon-equivalent

${ }^{\mathrm{c}}$ Billion 2001 US\$ using exchanges rates
}

\subsection{Domestic production}

Figure 1 represents the structure of the production sector in the model. Production technologies are described through nested CES functions. At this stage, we distinguish three different types of representation depending on the characteristics of the sector: sectors including a fixed factor, industry of refined petroleum, other sectors.

\subsubsection{Sectors including a fixed factor}

Sectors including a fixed factor are the coal, crude oil and natural gas industries. The fixed factor represents the non renewable resources associated with each fossil fuel energy. For these sectors we suppose that the domestic production 


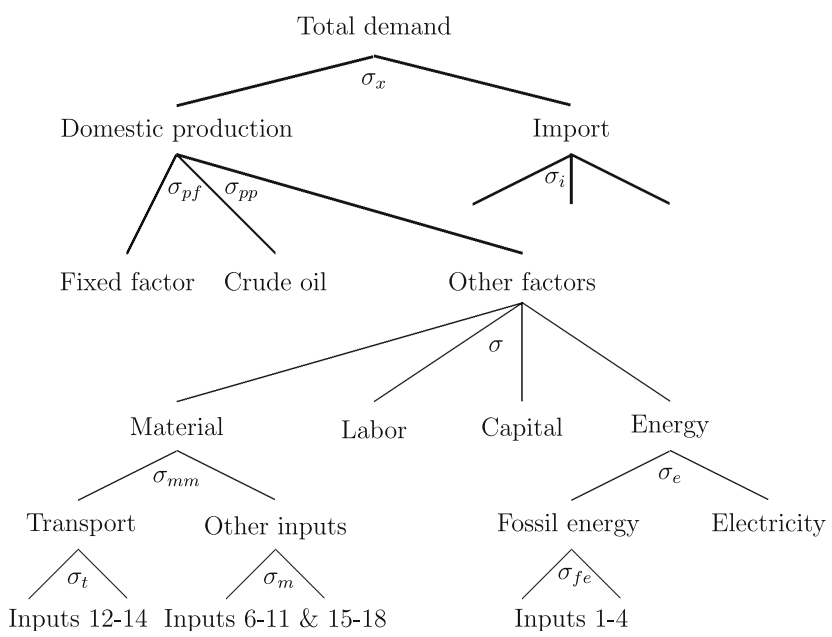

Fig. 1 Structure of the production sector in GEMINI-E3

is realized with this fixed factor and the other standard inputs through a CES function. This specification allows us to take into account the existing resources and its dynamics and the low substitutability between these resources and other inputs. Domestic production $\left(X P F_{i r}\right)$ is thus computed through the formula:

$$
X P F_{i r}=Y_{i r} \cdot \lambda_{i r}^{x} \cdot \alpha_{i r}^{x} \cdot\left[\frac{P Y_{i r}}{\lambda_{i r}^{x} \cdot P D F_{i r}}\right]^{\sigma_{i r}^{x}} \quad \forall i=1,2,3
$$

and is decomposed between fixed factor $\left(F F_{i r}\right)$ and standard inputs consumption $\left(X_{i r}\right)$ through a CES function:

$$
F F_{i r}=X P F_{i r} \cdot \lambda_{i r}^{p f} \cdot\left(1-\alpha_{i r}^{p f}\right) \cdot\left[\frac{P D F_{i r}}{\lambda_{i r}^{p f} \cdot P F_{i r}}\right]^{\sigma_{i r}^{p f}} \quad \forall i=1,2,3
$$

and $\left(X_{i r}\right)$ is equal to

$$
X_{i r}=X P F_{i r} \cdot \lambda_{i r}^{p f} \cdot \alpha_{i r}^{p f} \cdot\left[\frac{P D F_{i r}}{\lambda_{i r}^{p f} \cdot P D_{i r}}\right]^{\sigma_{i r}^{p f}} \quad \forall i=1,2,3
$$

where $P D F_{i r}$ is the price of domestic production for sectors $1,2,3, P F_{i r}$ is the price of the fixed factor and $P D_{i r}$ the price of other inputs (i.e standard inputs).

\subsubsection{Refined petroleum industry}

Refined petroleum products are produced from the basic input, that is crude oil. The model takes into account this specificity with a CES function between 
crude oil and other inputs at the top level of the nested CES structure. Domestic production of petroleum products $\left(X P P_{4 r}\right)$ is then equal to:

$$
X P P_{4 r}=Y_{4 r} \cdot \lambda_{4 r}^{x} \cdot \alpha_{4 r}^{x} \cdot\left[\frac{P Y_{4 r}}{\lambda_{4 r}^{x} \cdot P D P_{4 r}}\right]^{\sigma_{4 r}^{x}}
$$

crude oil used by refined petroleum sector $\left(I C_{24 r}\right)$ equal to:

$$
I C_{24 r}=X P P_{4 r} \cdot \lambda_{4 r}^{p p} \cdot\left(1-\alpha_{4 r}^{p p}\right) \cdot\left[\frac{P D P_{4 r}}{\lambda_{4 r}^{p p} \cdot P I C_{24 r}}\right]^{\sigma_{4 r}^{p p}}
$$

and standard inputs consumption $\left(X_{4 r}\right)$ equal to

$$
X_{4 r}=X P P_{4 r} \cdot \lambda_{4 r}^{p p} \cdot \alpha_{4 r}^{p p} \cdot\left[\frac{P D P_{4 r}}{\lambda_{4 r}^{p p} \cdot P D_{4 r}}\right]^{\sigma_{4 r}^{p p}}
$$

where $P D P_{4 r}$ is the price of domestic production for refined petroleum products, $P I C_{24 r}$ is the price of crude oil and $P D_{4 r}$ the price of other inputs (i.e standard inputs).

\subsubsection{Other sectors}

For the other sectors domestic production $\left(X_{i r}\right)$ is equal to

$$
X_{i r}=Y_{i r} \cdot \lambda_{i r}^{x} \cdot \alpha_{i r}^{x} \cdot\left[\frac{P Y_{i r}}{\lambda_{i r}^{x} \cdot P D_{i r}}\right]^{\sigma_{i r}^{x}} \quad \forall i=5, \ldots, 18
$$

where $P D_{\text {ir }}$ is the price of domestic production.

\subsection{Aggregated inputs}

$X_{i r}$ is realized with four aggregated inputs: capital $\left(K_{i r}\right)$, labor $\left(L_{i r}\right)$, energy $\left(E_{i r}\right)$, and material $\left(M A_{i r}\right)$. Demand for these factors are then equal to:

$$
\begin{aligned}
& K_{i r} \cdot \theta_{i r}^{k^{t}}=X_{i r} \cdot \lambda_{i r} \cdot \alpha_{i r}^{k} \cdot\left[\frac{P D_{i r}}{P K_{i r} \cdot \lambda_{i r} \cdot \theta_{i r}^{k^{-t}}}\right]^{\sigma_{i r}} \\
& L_{i r} \cdot \theta_{i r}^{l^{t}}=X_{i r} \cdot \lambda_{i r} \cdot \alpha_{i r}^{l} \cdot\left[\frac{P D_{i r}}{P L_{i r} \cdot \lambda_{i r} \cdot \theta_{i r}^{l}}\right]^{\sigma_{i r}} \\
& E_{i r} \cdot \theta_{i r}^{e t}=X_{i r} \cdot \lambda_{i r} \cdot \alpha_{i r}^{e} \cdot\left[\frac{P D_{i r}}{P E_{i r} \cdot \lambda_{i r} \cdot \theta_{i r}^{e-t}}\right]^{\sigma_{i r}}
\end{aligned}
$$




$$
M A_{i r} \cdot \theta_{i r}^{m t}=X_{i r} \cdot \lambda_{i r} \cdot\left(1-\alpha_{i r}^{k}-\alpha_{i r}^{l}-\alpha_{i r}^{e}\right) \cdot\left[\frac{P D_{i r}}{P M_{i r} \cdot \lambda_{i r} \cdot \theta_{i r}^{m-t}}\right]^{\sigma_{i r}}
$$

where $\theta_{i r}^{k}, \theta_{i r}^{l}, \theta_{i r}^{e}$ and $\theta_{i r}^{m}$ represent the technical progress incorporated respectively in capital, labor, energy and material.

\subsection{Energy consumption by sector}

Demand for energy $\left(E_{i r}\right)$ is allocated between aggregate fossil fuel consumption $\left(E F_{\text {ir }}\right)$ and electricity $\left(I C_{5 i r}\right)$ :

$$
\begin{aligned}
& E F_{i r}=E_{i r} \cdot \lambda_{i r}^{e} \cdot \alpha_{i r}^{e e} \cdot\left[\frac{P E_{i r}}{\lambda_{i r}^{e} \cdot P E F_{i r}}\right]^{\sigma_{i r}^{e}} \\
& I C_{5 i r}=E_{i r} \cdot \lambda_{i r}^{e} \cdot\left(1-\alpha_{i r}^{e e}\right) \cdot\left[\frac{P E_{i r}}{\lambda_{i r}^{e} \cdot P I C_{5 i r}}\right]^{\sigma_{i r}^{e}}
\end{aligned}
$$

and demand for each fuel through another CES function:

$$
I C_{k i r}=E F_{i r} \cdot \lambda_{i r}^{e f} \cdot \alpha_{k i r}^{e f} \cdot\left[\frac{P E F_{i r}}{\lambda_{i r}^{e f} \cdot P I C_{k i r}}\right]^{\sigma_{i r}^{e f}} \quad \forall k=1,3,4
$$

2.6 Material consumption by sector

Material consumption is allocated between two sub-aggregates, transport services $\left(T R_{i r}\right)$ and other material inputs $\left(O T R_{i r}\right)$ :

$$
\begin{gathered}
T R_{i r}=M A_{i r} \cdot \lambda_{i r}^{m m} \cdot \alpha_{i r}^{m m} \cdot\left[\frac{P M_{i r}}{\lambda_{i r}^{m m} \cdot P T R_{i r}}\right]^{\sigma_{i r}^{m m}} \\
O T R_{i r}=M A_{i r} \cdot \lambda_{i r}^{m m} \cdot\left(1-\alpha_{i r}^{m m}\right) \cdot\left[\frac{P M_{i r}}{\lambda_{i r}^{m m} \cdot P O T R_{i r}}\right]^{\sigma_{i r}^{m m}}
\end{gathered}
$$

which are then allocated between products according to two CES functions:

$$
\begin{aligned}
& I C_{k i r}=T R_{i r} \cdot \lambda_{i r}^{r} \cdot \alpha_{k i r}^{r} \cdot\left[\frac{P T R_{i r}}{\lambda_{i r}^{r} \cdot P I C_{k i r} \cdot}\right]^{\sigma_{i r}^{r}} \quad \forall k=12,13,14 \\
& I C_{k i r}=O T R_{i r} \cdot \lambda_{i r}^{m} \cdot \alpha_{k i r}^{m} \cdot\left[\frac{P O T R_{i r}}{\lambda_{i r}^{m} \cdot P I C_{k i r}}\right]^{\sigma_{i r}^{m}} \quad \forall k=6 \ldots 11,15 \ldots 18
\end{aligned}
$$


2.7 Final demand

\subsubsection{Households behavior}

Household's behavior consists in three interdependent decisions: (1) labor supply; (2) savings; and (3) consumption of the various goods and services. In GEMINI-E3, we suppose that both labor supply and the rate of savings are exogenous. Demand in the different commodities has prices of consumption and income (more precisely "spent" income, income after savings) as arguments and is derived from an utility function whose specifications, as in most CGE models, are a Stone-Geary (1983) or linear expenditure system (LES):

$$
u_{r}=\sum_{i} \beta_{i r} \cdot \ln \left(H C_{i r}-\phi_{i r}\right)
$$

where $\phi_{i r}$ represents the minimum necessary purchase of good $i$, and $\beta_{i r}$ corresponds to the marginal budget share of good $i$.

Maximization under budget constraint where $H C T_{r}$ represents the total expenditure for households consumption, and where $P C_{i r}$ is the price of consumption, gives the demand function:

$$
H C_{i r}=\phi_{i r}+\frac{\beta_{i r}}{P C_{i r}} \cdot\left[H C T_{r}-\sum_{k}\left(P C_{k r} \cdot \phi_{k r}\right)\right]
$$

\subsubsection{Government consumption}

Total government consumption $\left(G C T_{r}\right)$ is exogenous and its evolution over time, determined in the calibration of the model, is driven by the growth rates of the main aggregates of the economy. The model splits total consumption between goods $\left(G C_{i r}\right)$ on the basis of budget shares $\beta_{i r}^{g}$ :

$$
G C_{i r}=\beta_{i r}^{g} \cdot G C T_{r}
$$

\subsubsection{Investment}

Investment by product $\left(I V_{i r}\right)$ is derived from investment by sector $\left(I_{k r}\right)$ through a transfer matrix $\Phi_{i k r}$ :

$$
I V_{i r}=\sum_{k} \Phi_{i k r} \cdot I_{k r}
$$

\subsubsection{Exports}

In GEMINI-E3 as in any world CGE model, there is no function of exports. For each country/region and each good, the exports $\left(E X_{i r}\right)$ are the sum of demands by all other countries/regions that are endogenously determined in the model: 


$$
E X_{i r}=\sum_{h} M R_{i r h}
$$

\subsection{The price system}

The relations determining the prices of composite goods $\left(P Y_{i r}\right)$, of domestic production $\left(P D_{i r}, P D F_{i r}, P D P_{i r}\right)$, of energy $\left(P E_{i r}\right)$, of fossil fuel $\left(P E F_{i r}\right)$, of material $\left(P M_{i r}\right)$, of transport services $\left(P T R_{i r}\right)$ and of other material inputs $\left(P O T R_{i r}\right)$ are derived from the production function, through its nested CES architecture:

$$
\begin{aligned}
& P Y_{i r}=\lambda_{i r}^{x} \cdot\left[\alpha_{i r}^{x} \cdot P D_{i r}^{1-\sigma_{i r}^{x}}+\left(1-\alpha_{i r}^{x}\right)\right. \\
& \left.\cdot\left(P I_{i r} \cdot\left(1+\kappa_{i r}^{i}\right)\right)^{1-\sigma_{i r}^{x}}\right]^{\frac{1}{1-\sigma_{i r}^{x}}} \quad \forall i=5, \ldots, 18 \\
& P Y_{i r}=\lambda_{i r}^{x} \cdot\left[\alpha_{i r}^{x} \cdot P D F_{i r}^{1-\sigma_{i r}^{x}}+\left(1-\alpha_{i r}^{x}\right)\right. \\
& \left.\cdot\left(P I_{i r} \cdot\left(1+\kappa_{i r}^{i}\right)\right)^{1-\sigma_{i r}^{x}}\right]^{\frac{1}{1-\sigma_{i r}^{x}}} \quad \forall i=1,2,3 \\
& P Y_{i r}=\lambda_{i r}^{x} \cdot\left[\alpha_{i r}^{x} \cdot P D P_{i r}^{1-\sigma_{i r}^{x}}+\left(1-\alpha_{i r}^{x}\right)\right. \\
& \left.\cdot\left(P I_{i r} \cdot\left(1+\kappa_{i r}^{i}\right)\right)^{1-\sigma_{i r}^{x}}\right]^{\frac{1}{1-\sigma_{i r}^{x}}} \quad \forall i=4 \\
& P D F_{i r}=\lambda_{i r}^{p f} \cdot\left[\alpha_{i r}^{p f} \cdot P D_{i r}^{1-\sigma_{i r}^{p f}}+\left(1-\alpha_{i r}^{p f}\right) \cdot P F_{i r}^{1-\sigma_{i r}^{p f}}\right]^{\frac{1}{1-\sigma_{i r}^{p f}}} \quad \forall i=1,2,3 \\
& P D P_{i r}=\lambda_{i r}^{p p} \cdot\left[\alpha_{i r}^{p p} \cdot P D_{i r}^{1-\sigma_{i r}^{p p}}+\left(1-\alpha_{i r}^{p p}\right) \cdot P I C_{24 r}^{1-\sigma_{i r}^{p p}}\right]^{\frac{1}{1-\sigma_{i r}^{p p}}} \quad \forall i=4 \\
& P D_{i r}=\lambda_{i r} \cdot\left[\alpha_{i r}^{k} \cdot\left(\frac{P K_{i r}}{\theta_{i r}^{k^{t}}}\right)^{1-\sigma_{i r}}+\alpha_{i r}^{l} \cdot\left(\frac{P L_{i r}}{\theta_{i r}^{l}}\right)^{1-\sigma_{i r}}\right. \\
& \left.+\alpha_{i r}^{e} \cdot\left(\frac{P E_{i r}}{\theta_{i r}^{e t}}\right)^{1-\sigma_{i r}}+\left(1-\alpha_{i r}^{k}-\alpha_{i r}^{l}-\alpha_{i r}^{e}\right) \cdot\left(\frac{P M_{i r}}{\theta_{i r}^{m t}}\right)^{1-\sigma_{i r}}\right]^{\frac{1}{1-\sigma_{i r}}} \\
& P E_{i r}=\lambda_{i r}^{e} \cdot\left[\alpha_{i r}^{e e} \cdot P E F_{i r}^{1-\sigma_{i r}^{e}}+\left(1-\alpha_{i r}^{e e}\right) \cdot P I C_{5 i r}^{1-\sigma_{i r}^{e}}\right]^{\frac{1}{1-\sigma_{i r}^{e}}} \\
& E F_{i r}=\lambda_{i r}^{e f} \cdot\left[\sum_{k=1,3,4} \alpha_{k i r}^{e f} \cdot P I C_{k i r}^{1-\sigma_{i r}^{e f}}\right]^{\frac{1}{1-\sigma_{i r}^{e f}}} \\
& P M_{i r}=\lambda_{i r}^{m m} \cdot\left[\alpha_{i r}^{m m} \cdot P T R_{i r}^{1-\sigma_{i r}^{m m}}+\left(1-\alpha_{i r}^{m m}\right) \cdot P O T R_{i r}^{1-\sigma_{i r}^{m m}}\right]^{\frac{1}{1-\sigma_{l r}^{m m}}}
\end{aligned}
$$




$$
\begin{gathered}
P T R_{i r}=\lambda_{i r}^{r} \cdot\left[\sum_{k=12,13,14} \alpha_{k i r}^{r} \cdot P I C_{k i h}^{1-\sigma_{i r}^{r}}\right]^{\frac{1}{1-\sigma_{i r}^{r}}} \\
\operatorname{POTR}_{i r}=\lambda_{i r}^{m} \cdot\left[\sum_{k=6 . .11,15 . .18} \alpha_{k i r}^{m} \cdot P I C_{k i h}^{1-\sigma_{i r}^{m}}\right]^{\frac{1}{1-\sigma_{i r}^{m}}}
\end{gathered}
$$

The equations for base price $\left(P B_{i r}\right)$ including tax on production, price of consumption $\left(P C_{i r}\right)$, government consumption $\left(P G_{i r}\right)$, intermediate consumption $\left(P I C_{i r}\right)$, investment $\left(P V_{i r}\right)$, labor $\left(P L_{i r}\right)$, exports $\left(P X_{i r}\right)$, and imports $\left(P I_{i r}\right)$ are then:

$$
\begin{gathered}
P B_{i r}=\frac{P Y_{i r}}{\left(1-\kappa_{i r}^{b}\right)} \\
P C_{i r}=\left(P B_{i}+\kappa_{i r}^{e}\right) \cdot\left(1+\kappa_{i r}^{h}\right)+\tau_{i r}^{h} \cdot T C O 2_{r} \\
P G_{i r}=P B_{i r} \cdot\left(1+\kappa_{i r}^{g}\right)+\tau_{i r}^{g} \cdot T C O 2_{r} \\
P I C_{i k r}=P B_{i r} \cdot\left(1+\kappa_{i k r}^{i}\right)+\tau_{i k r}^{i} \cdot T C O 2_{r} \\
P V_{i r}=\sum_{k}\left(P B_{k r} \cdot \Phi_{k i r} \cdot\left(1+\kappa_{k i r}^{v}\right)\right) \\
P L_{i r}=W_{r} \cdot\left(1+\kappa_{i r}^{w}\right) \\
P X_{i r}=P B_{i r} \cdot\left(1+\kappa_{i r}^{x}\right) \\
P I_{i r}=\lambda_{i r}^{i} \cdot\left[\sum_{h} \alpha_{i h r}^{i} \cdot\left[P X_{i h} \cdot\left(e_{h} / e_{r}\right)\right]^{1-\sigma_{i r}^{a i}}\right]^{\frac{1}{1-\sigma_{l r}^{a l}}}
\end{gathered}
$$

where $\kappa_{i r}^{b}$ is the tax rate on production, $\kappa_{i r}^{h}, \kappa_{i r}^{g}, \kappa_{i k r}^{i}, \kappa_{i r}^{v}$ are Value Added Tax rates ${ }^{4}$ respectively on household consumption, government consumption, intermediate consumption and investment, $\kappa_{i r}^{e}$ represents the excises (mainly on motor fuel), $\kappa_{i r}^{w}$ is tax linked to wages (mainly social contribution), $\kappa_{i r}^{i}$ import duties rate and $\kappa_{i r}^{x}$ export subsidies rate. $\tau_{i r}^{h}, \tau_{i r}^{g}, \tau_{i k r}^{i}$ are the carbon content of one unit of respectively household consumption, government consumption and intermediate consumption and $\mathrm{TCO} 2_{r}$ is the carbon tax.

\subsection{Capital accumulation}

The stock of capital by sector $\left(K C_{i r}\right)$ is determined by the classical accumulation formula, with gross investment as input and physical depreciation as output:

4 Or tax on sales with different tax rates depending on fiscal system of the regions. 


$$
K C_{i r}=\left(1-\delta_{i r}\right) \cdot K C_{i r}^{t-1}+I_{i r}^{t-1}
$$

where $\delta_{i r}$ is the rate of capital decay, investment by sector is determined from an "anticipated" capital demand:

$$
I_{i r}=K A_{i r}-\left(1-\delta_{i r}\right) \cdot K C_{i r}
$$

where the anticipated capital $\left(K A_{\text {ir }}\right)$ is equal to:

$$
K A_{i r}=\left(1-\chi_{i r}\right) \cdot K O_{i r}+\chi_{i r} \cdot\left(\frac{K C_{i r}^{2}}{K C_{i r}^{t-1}}\right)
$$

and where $K O_{i r}$ the optimal capital is computed through a CES function and anticipated values of prices $\left(P D A_{i r}, P V A_{i r}\right)$ and of domestic production $\left(X A_{i r}\right)$ :

$$
K O_{i r} \cdot \theta_{i r}^{k^{t+1}}=X A_{i r} \cdot \lambda_{i r} \cdot \alpha_{i r}^{k} \cdot\left(\frac{P D A_{i r}}{P V A_{i r} \cdot \frac{R_{r}+\delta_{i r}}{1+\kappa_{i r}^{k}} \cdot \theta_{i r}^{k^{-t-1}}}\right)^{\sigma_{i r}}
$$

with $R_{r}$ the interest rate and $\kappa_{i r}^{k}$ is the tax rate on capital income.

The demand for capital is computed through a CES function (see Eq. 11). The demand for capital $\left(K_{i r}\right)$ is equal to supply $\left(K C_{i r}\right)$ through the rental price of capital $\left(P K_{i r}\right)$, see Eq. 56.

\subsection{Government budget and Government surplus or deficit}

The Government surplus or deficit is the difference between revenues accruing from taxation (direct and indirect, including social security contributions) and expenditures that are of two types: public consumption and transfers to households [mainly social benefits $\left(S B_{r}\right)$ ]:

$$
\begin{aligned}
S G_{r}= & \sum_{i} Y_{i r} \cdot \frac{\kappa_{i r}^{b} \cdot P Y_{i r}}{\left(1-\kappa_{i r}^{b}\right)}+\sum_{i} P B_{i r} \cdot \kappa_{i r}^{h} \cdot H C_{i r}+\sum_{i} P B_{i r} \cdot \kappa_{i r}^{g} \cdot G C_{i r} \\
& +\sum_{i} P I_{i r} \cdot \kappa_{i r}^{i} \cdot M_{i r}+\sum_{i} P B_{i r} \cdot \kappa_{i r}^{x} \cdot E X_{i r}+\sum_{i} W_{r} \cdot \kappa_{i r}^{w} \cdot L_{i r} \\
& +\sum_{i} P B_{i r} \cdot \sum_{k} \Phi_{i k r} \cdot \kappa_{k i r}^{v} \cdot I_{k r}+\sum_{k} P B_{k r} \cdot \sum_{i} I C_{k i r} \cdot \kappa_{k i r}^{i} \\
& +\sum_{i} K_{i r} \cdot P K_{i r} \cdot \kappa_{i r}^{k}+\sum_{i=1,4} H C_{i r} \cdot \tau_{i r}^{h} \cdot T C O 2_{r}+\sum_{i=1,4} G C_{i r} \cdot \tau_{i r}^{g} \cdot T C O 2_{r} \\
& +\sum_{k} \sum_{i=1,4} I C_{i k r} \cdot \tau_{i k r}^{i} \cdot T C O 2_{r}+\kappa_{r}^{r} \cdot R E V_{r}-\sum_{i}\left(G C_{i r} \cdot P G_{i r}\right)-S B_{r}
\end{aligned}
$$

where $\kappa_{r}^{r}$ represents the rate of direct taxation. 


\subsection{Households budget}

Households' savings is determined by the product of income (net of direct taxes and other similar contributions) $R E V_{r}$ and the rate of savings $\zeta_{r}$ :

$$
\begin{gathered}
R E V_{r}=W_{r} \cdot \sum_{i} L_{i r}+\sum_{i} K_{i r} \cdot P K_{i r} \cdot\left(1-\kappa_{i r}^{k}\right)+\sum_{i} F F_{i r} \cdot P F_{i r}+S B_{r} \\
S H_{r}=R E V_{r} \cdot\left(1-\kappa_{r}^{r}\right) \cdot \zeta_{r}
\end{gathered}
$$

By difference, one obtains the aggregate households' consumption that is then allocated in the demand for the various commodities.

$$
H C T_{r}=R E V_{r} \cdot\left(1-\kappa_{r}^{r}\right)-S H_{r}
$$

\subsection{Carbon emissions}

Carbon emissions by region are computed from energy consumption by the formula:

$$
C O 2_{r}=\sum_{i=1,4} \sum_{k} I C_{i k r} \cdot \tau_{i k r}^{i}+\sum_{i=1,4} H C_{i r} \cdot \tau_{i k r}^{h}+\sum_{i=1,4} G C_{i r} \cdot \tau_{i k r}^{g}
$$

\subsection{General equilibrium conditions}

The equations below present the clearing market conditions for the various goods, factors of production and balancing conditions between investment and savings on the one hand, imports and exports on the other hand:

$$
L S_{r}=\sum_{i} L_{i r}\left(R_{r}\right) \quad \forall r
$$

where $L S_{r}$ is the supply of labor by households (set exogenously).

$$
\begin{aligned}
K_{i r} & =K C_{i r}\left(P K_{i r}\right) \quad \forall i \quad \forall r \\
F F_{i r} & =F S_{\text {ir }}\left(P F_{i r}\right) \quad \forall i=1,2,3 \quad \forall r
\end{aligned}
$$

where $F S_{i r}$ is the supply of fixed factor (fixed exogenously).

$$
\varepsilon_{r}=S G_{r}\left(\kappa_{r}^{r}\right) \quad \forall r
$$

It is assumed that in the scenarios the government surplus or deficit remains the same as in the baseline scenario. $\varepsilon_{r}$.

$$
\sum_{i} M_{i r} \cdot P I_{i r}=\sum_{i} E X_{i r} \cdot P X_{i r}\left(e_{r}\right) \quad \forall r=1, \ldots, 27
$$


Of course if $n-1$ trade balances are cleared the trade balance of region 28 is balanced.

$$
C O 2_{r}=C O 2 Q_{r}\left(T C O 2_{r}\right) \quad \forall r
$$

where $C O 2 Q_{r}$ is the constraint for carbon emissions.

General equilibrium relations also include balancing of operations for all agents but, due to the well-known Walras Law, all but one must be taken into account in the resolution of the model. Variables in brackets are those used in the computational algorithm and associated to the corresponding relation.

$$
S H_{i r}+S G_{i r}=\sum_{i} I V_{i r} \cdot P V_{i r} \quad \forall r
$$

\subsection{Non carbon greenhouse gas emissions}

In the initial version of the model, only carbon dioxide emissions were taken into account. In the present version, and capitalizing from participation to the EMF Working Group 21 (Van Vuuren et al. 2006; Weyant et al. 2006; Scheehle and Kruger 2006; Delhotal et al. 2006; Schaefer et al. 2006; DeAngelo et al. 2006), the model has been updated in order to fully integrate all GHG emissions. ${ }^{5}$ For non $\mathrm{CO}_{2}$ greenhouse gases data on emissions and abatement costs come from the U.S. Environmental Protection Agency (2006). We take into account all the direct GHGs covered by the United Nations Framework Convention on Climate Change: methane, nitrous oxide, and the high global warming potential (GWP) gases. Emissions of non carbon greenhouse emissions are converted to a $\mathrm{CO}_{2}$-equivalent basis using the 100-year GWPs defined by the Intergovernmental Panel on Climate Change (Houghton et al. 1997).

U.S. Environmental Protection Agency estimates that world GHG emissions in 2000 were 41382 millions metric ton of $\mathrm{CO}_{2}$ equivalents. Figure 2 shows the contribution of non carbon greenhouse gas emissions. They represent $23 \%$ of global greenhouse gas emissions, methane accounts for $15 \%$, nitrous oxide for $8 \%$ and high global warming potential gases for $1 \%$.

\subsubsection{Methane}

The model takes into account 13 sources of $\mathrm{CH}_{4}$ emissions. The emissions of each source are linked to an activity level (or an economic driver) the coefficient of which is calibrated on the baseline scenario:

$$
N C O 2_{l r}=\frac{v_{l r}}{\theta_{l r}{ }^{t}} \cdot E D_{l r}
$$

\footnotetext{
5 A version of the model taking into account only carbon emissions has been kept for special applications.
} 


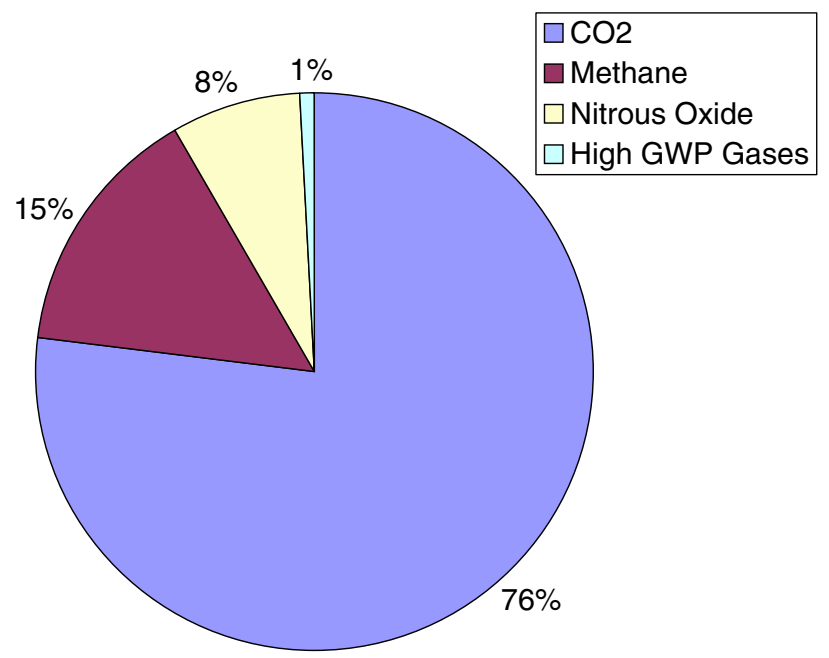

Fig. 2 Breakdown by gas of World GHG emissions (source United States Environmental Protection Agency 2006)

where $E D_{l r}$ is the economic driver, $v_{l r}$ a coefficient representing the amount of source $l$ emitted by the economic driver and $\theta_{l r}$ an exogenous technical progress on the coefficient $v_{l r}$.

The Table 3 shows the correspondence between the sources and the sectors/products in GEMINI-E3, the variable of the model representing the economic driver, and whether an abatement curve (MAC) is available for this source.

Table 3 Methane and GEMINI-E3 activities

\begin{tabular}{|c|c|c|c|}
\hline Source & $\operatorname{Index}(l)^{\mathrm{a}}$ & Economic drivers & MAC \\
\hline Landfilling of solid waste & LAN & Total household consumption & Yes \\
\hline Biomass combustion & $\mathrm{BIC}$ & Total household consumption & \\
\hline $\begin{array}{l}\text { Fugitives from coal mining } \\
\text { activities }\end{array}$ & $\mathrm{COA}$ & Agriculture production & Yes \\
\hline Enteric fermentation & ENT & Agriculture production & Yes \\
\hline $\begin{array}{l}\text { Stationary and mobile } \\
\text { combustion }\end{array}$ & FUE & $\begin{array}{l}\text { Total Demand of refined petro- } \\
\text { leum }\end{array}$ & \\
\hline $\begin{array}{l}\text { Other industrial } \\
\text { non-agricultural sources }\end{array}$ & IND & Chemical production & \\
\hline Oil & OIL & Crude oil production & Yes \\
\hline Manure management & MAN & Agriculture production & Yes \\
\hline Rice cultivation & RIC & Agriculture production & Yes \\
\hline Other agricultural sources & OAG & Agriculture production & Yes \\
\hline Wastewater & WAS & Total household consumption & \\
\hline $\begin{array}{l}\text { Other non-agricultural sources } \\
\text { (waste and other) }\end{array}$ & OTH & Total household consumption & \\
\hline Natural gas & GAS & Total demand of natural gas & Yes \\
\hline
\end{tabular}

${ }^{a}$ For example the index in the case of emissions coming from coal mining is noted $\mathrm{CH} 4{ }^{\mathrm{Coa}}$ 
Table 4 Nitrous oxide and GEMINI-E3 activities

\begin{tabular}{|c|c|c|c|}
\hline Source & $\operatorname{Index}(l)^{\mathrm{a}}$ & Economic drivers & MAC \\
\hline Agricultural Soils & AGS & Agriculture production & \\
\hline Other agricultural sources & OAG & Agriculture production & \\
\hline Biomass combustion & $\mathrm{BIC}$ & Total household consumption & \\
\hline $\begin{array}{l}\text { Stationary and mobile } \\
\text { combustion }\end{array}$ & FUE & $\begin{array}{l}\text { Total demand of refined petro- } \\
\text { leum }\end{array}$ & \\
\hline Manure management & MAN & Agriculture production & \\
\hline $\begin{array}{l}\text { Other non-agricultural sources } \\
\text { (waste and other) }\end{array}$ & OTH & Total household consumption & \\
\hline $\begin{array}{l}\text { Other industrial non-agricultural } \\
\text { sources }\end{array}$ & OIN & $\begin{array}{l}\text { Metal and metal goods produc- } \\
\text { tion }\end{array}$ & \\
\hline Adipic acid production & ADI & Chemical production & Yes \\
\hline Nitric acid production & NIT & Chemical production & Yes \\
\hline Human sewage & HUM & Total household consumption & \\
\hline
\end{tabular}

${ }^{\text {a }}$ For example the index in the case of emissions coming from adipic acid production is noted N20 Adi

\subsubsection{Nitrous oxide}

For $\mathrm{N}_{2} \mathrm{O}$ emissions we adopt the same formulation and the Table 4 gives the economic driver for the ten sources of emission.

\subsubsection{High global warming potential gases}

High global warming potential gas emissions result from the use of substitutes for ozone-depleting substances, from the production of magnesium, aluminum, semiconductors, flat panel display, HCFC-22, electrical equipment and from the use of electrical equipment. GEMINI-E3 distinguishes 11 types of fluorinated gases, they are presented in Table 5.

\subsubsection{Curve of abatement}

Abatement is computed on the basis of the EMF21 abatement curves (Delhotal et al. 2006; Schaefer et al. 2006; DeAngelo et al. 2006) updated in United States Environmental Protection Agency (2006). In this report marginal abatement cost curves for each region and sector are constructed by estimating the carbon price at which the present value benefits and costs for each mitigation option equilibrate. The methodology produces a stepwise curve, where each point reflects the average price and reduction potential if a mitigation technology were applied across the sector within a given region. These curves have the generic form described in Fig. 3.

We can then compute the level of emissions on the basis of a $\mathrm{CO}_{2}$ tax:

$$
N C O 2_{l r}=\frac{v_{l r}}{\theta_{l r}{ }^{t}} \cdot\left[1-f_{l r}\left(T C O 2_{r}\right)\right] \cdot E D_{l r}
$$


Table 5 High global warming potential gases and GEMINI-E3 activities

\begin{tabular}{|c|c|c|c|}
\hline Source & Index $(l)$ & Economic drivers & MAC \\
\hline $\begin{array}{l}\text { ODS substitutes aerosols } \\
\text { (Non-MDI) }\end{array}$ & PFC_AEN & Total household consumption & Yes \\
\hline $\begin{array}{l}\text { ODS substitutes fire } \\
\text { Extinguishing }\end{array}$ & PFC_FIR & Total household consumption & Yes \\
\hline ODS substitutes foams & PFC_FOA & Total household consumption & Yes \\
\hline ODS substitutes solvents & PFC_SOL & Total household consumption & Yes \\
\hline ODS Substitutes aerosols (MDI) & PFC_AEM & Total household consumption & \\
\hline $\begin{array}{l}\text { ODS substitutes refrigeration/ } \\
\text { air conditioning }\end{array}$ & PFC_REF & Total household consumption & Yes \\
\hline $\begin{array}{l}\text { HFC- } 23 \text { emissions from } \\
\text { HCFC- } 22 \text { production }\end{array}$ & HFC_22 & Total Household consumption & Yes \\
\hline $\begin{array}{l}\text { SF6 emissions from electric } \\
\text { power systems }\end{array}$ & SF6_EPS & $\begin{array}{l}\text { Metal and metal goods } \\
\text { production }\end{array}$ & Yes \\
\hline $\begin{array}{l}\text { PFC emissions from primary } \\
\text { aluminum production }\end{array}$ & PFC_PAP & $\begin{array}{l}\text { Metal and metal goods } \\
\text { production }\end{array}$ & Yes \\
\hline $\begin{array}{l}\text { HFC, PFC, SF6 from } \\
\text { semiconductor manufacturing }\end{array}$ & PFC_SEM & Equipment goods production & Yes \\
\hline $\begin{array}{l}\text { SF6 emissions from magnesium } \\
\text { manufacturing }\end{array}$ & SF6_MAM & $\begin{array}{l}\text { Metal and metal goods } \\
\text { production }\end{array}$ & Yes \\
\hline
\end{tabular}

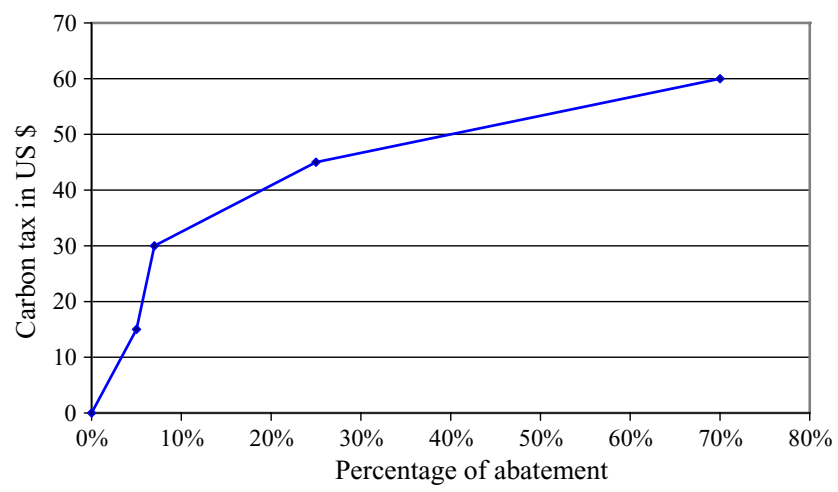

Fig. 3 Curve of marginal abatement costs

where $f_{l r}\left(T C O 2_{r}\right)$ is a linear approximation of the abatement curve given by United States Environmental Protection Agency (2006).

\subsubsection{Cost of abatement}

The cost of abatement is equal to:

$F_{l r}\left(T C O 2_{r}\right) \cdot \frac{v_{l r}}{\theta_{l r}{ }^{t}} \cdot E D_{l r} \cdot f_{l r}\left(T C O 2_{r}\right)$ in the case of emissions $l$, where $F_{l r}\left(T C O 2_{r}\right)$ is the integral of the function $f_{l r}{ }^{-1}$ in the interval $\left[0, f_{l r}\left(T C O 2_{r}\right)\right]$.

In order to avoid non-constant returns to scale in production functions, we suppose that the operational cost of abatement is borne by the government and consists in government consumption. 
Government consumption is then the sum of two terms (see Eq. 64): a "final" good, which is representative of various services for the economy and in particular for households; an "intermediate" good which is the abatement cost and is equal to $F_{l r}\left(T C O 2_{r}\right) \cdot \frac{v_{l r}}{\theta_{l r}{ }^{t}} \cdot E D_{l r} \cdot f_{l r}\left(T C O 2_{r}\right)$.

$$
G C_{i r}=\beta_{i r}^{g} \cdot\left(G C T_{r}+\frac{\sum_{l} F_{l r}\left(T C O 2_{r}\right) \cdot \frac{v_{l r}}{\theta_{l r}} \cdot E D_{l r} \cdot f_{l r}\left(T C O 2_{r}\right)}{\sum_{i} \beta_{i r}^{g} \cdot P G_{i r}}\right)
$$

This distinction is important for GEMINI-E3 because, in order to get relevant yearly measures of welfare cost, we implement the climate change scenarios at constant final demand except, obviously, households' final consumption and imports, and in particular at constant government "final" consumption and constant total investment $\left.{ }^{6}\right)$.

\subsubsection{Taxation of non carbon greenhouse gases}

Levies on non carbon greenhouse gases are incorporated into the price system: the model computes for all economic drivers the equivalent tax rates on base prices associated to these levies, according to the formula:

$$
\kappa_{i r}^{c}=\frac{T C O 2_{r} \cdot \sum_{l} \sum_{E D_{l r}\left(i f E D_{l r} \in i\right)} \frac{v_{l r}}{\theta_{l r}{ }^{t}} \cdot E D_{l r} \cdot\left(1-f_{l r}\left(T C O 2_{r}\right)\right)}{Y_{i r} \cdot \frac{P Y_{i r}}{1-\kappa_{i r}^{b}}}
$$

We then replace the base price equation (38) by:

$$
P B_{i r}=\frac{P Y_{i r}}{\left(1-\kappa_{i r}^{b}\right)} \cdot\left(1+\kappa_{i r}^{c}\right)
$$

we must now integrate tax revenues coming from non-carbon greenhouse gas emissions in the government budget and replace Eq. 50 by:

$$
\begin{aligned}
S G_{r}= & \sum_{i} Y_{i r} \cdot \frac{\kappa_{i r}^{b} \cdot P Y_{i r}}{\left(1-\kappa_{i r}^{b}\right)}+\sum_{i} P B_{i r} \cdot \kappa_{i r}^{h} \cdot H C_{i r}+\sum_{i} P B_{i r} \cdot \kappa_{i r}^{g} \cdot G C_{i r} \\
& +\sum_{i} P I_{i r} \cdot \kappa_{i r}^{i} \cdot M_{i r}+\sum_{i} P B_{i r} \cdot \kappa_{i r}^{x} \cdot E X_{i r}+\sum_{i} W_{r} \cdot \kappa_{i r}^{w} \cdot L_{i r} \\
& +\sum_{i} P B_{i r} \cdot \sum_{k} \Phi_{i k r} \cdot \kappa_{k i r}^{v} \cdot I_{k r}+\sum_{k} P B_{k r} \cdot \sum_{i} I C_{k i r} \cdot \kappa_{k i r}^{i} \\
& +\sum_{i} K_{i r} \cdot P K_{i r} \cdot \kappa_{i r}^{k}+\sum_{i=1,4} H C_{i r} \cdot \tau_{i r}^{h} \cdot T C O 2_{r}+\sum_{i=1,4} G C_{i r} \cdot \tau_{i r}^{g} \cdot T C O 2_{r}
\end{aligned}
$$

\footnotetext{
6 But of course with an endogenous allocation between sectors.
} 


$$
\begin{aligned}
& +\sum_{k} \sum_{i=1,4} I C_{i k r} \cdot \tau_{i k r}^{i} \cdot T C O 2_{r}+T C O 2_{r} \cdot \sum_{l} N C O 2_{l i} \\
& +\kappa_{r}^{r} \cdot R E V_{r}-\sum_{i}\left(G C_{i r} \cdot P G_{i r}\right)-S B_{r}
\end{aligned}
$$

finally we modify the equilibrium condition (Eq. 60):

$$
C O 2_{r}+\sum_{l} N C O 2_{l r}=G H G Q_{r}\left(T C O 2_{r}\right) \quad \forall r
$$

where $G H G Q_{r}$ is the constraint on GHG emissions.

\section{Calibration and data}

The building and the calibration of a CGE model rest on economic and energy data that are usually contained in comprehensive databases, specifically established for this purpose. The present version of GEMINI-E3 is built on GTAP-6 (Dimaranan 2006), a database that accommodates a consistent representation of energy markets in physical units as well as detailed socio-accounting matrices (SAM) (Reinert and Roland-Holst 1997) for a large set of countries or regions and bilateral trade flows.

The GTAP database is completed by other information especially on indirect taxation and government expenditures, mainly coming from International Energy Agency (International Energy Agency 2002a,b, 2005), OECD (Organisation For Economic Co-operation and Development 2003, 2005) and International Monetary Fund (2004). An important work must be done in order to harmonize all these sources of information. The result is for each country or region a consistent Social Accounting Matrix in the form described in the Fig. 4. Let us recall that the GTAP 6 database is relative to the year 2001 and then that the latter is the base year of the model. Concerning data on population we use the work done by the United Nations (2006).

The default values for elasticity parameters are reported in Table 6.

\section{Cost of pollution abatement: measurement and factors}

The cost of abatement policies, in their various possible ways of implementation, is a key indicator of the efficiency of climate change policies (Bernard and Vielle 2003). Effectively, when there exists a perfect substitute to the polluting good, or a de-polluting device, the additional cost of the good or of the device measures the welfare cost of abatement. In the case of the greenhouse effect, this is rarely possible, and the bulk of abatement results from the reduction of consumption of GHG emitting goods and their replacement by other factors or less emitting goods, through taxation and changes in relative prices. Measuring welfare cost is then more complex, and in particular macro-economic aggregates such 


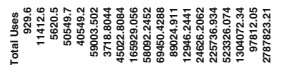

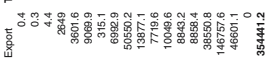

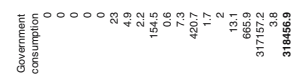

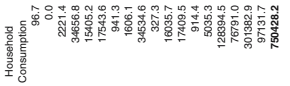 \\ 豆}

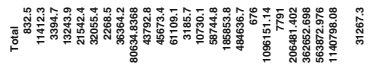

喜

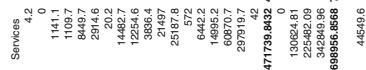

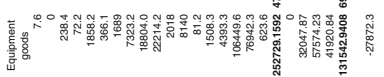

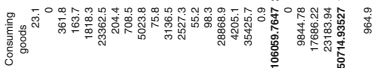

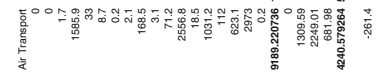

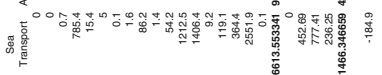

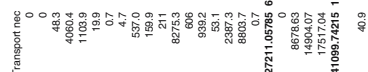

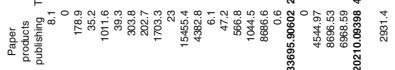

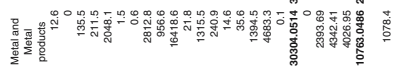

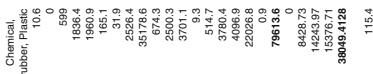

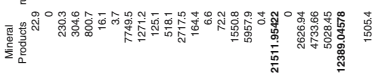

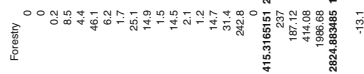

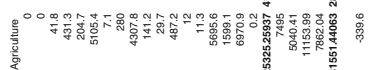

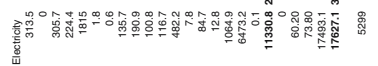

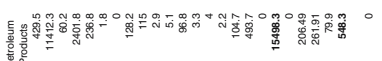

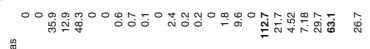

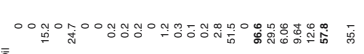

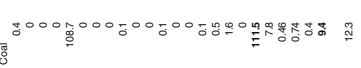

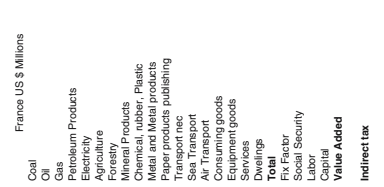

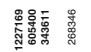

䈘要

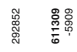

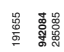

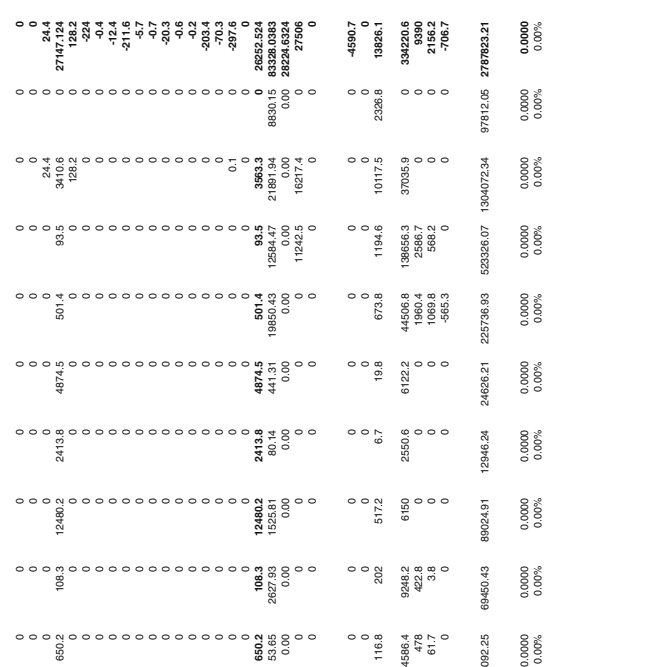

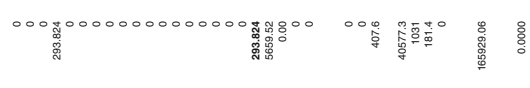

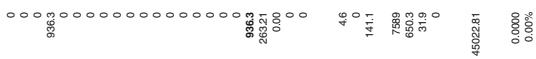

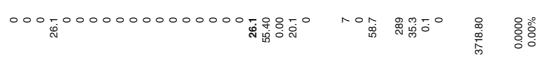

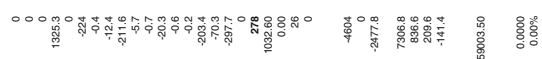

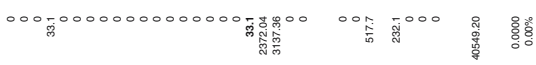

000000000000000000000

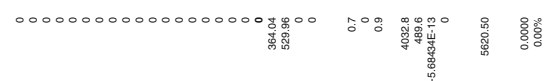

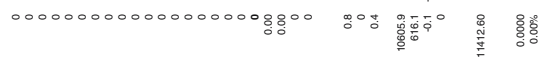

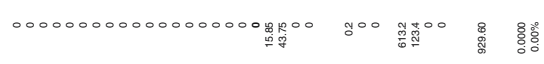

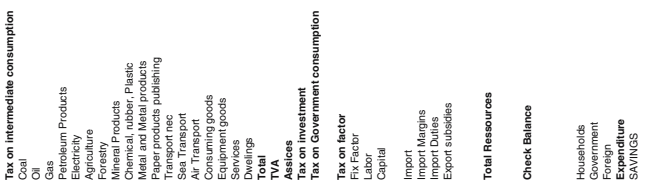

Fig. 4 Social accounting matrix 
Table 6 GEMINI-E3 default parameters

\begin{tabular}{lllllr}
\hline Parameter & Sector & Value & Parameter & Sector & Value \\
\hline$\sigma$ & All & 0.30 & $\sigma_{r}$ & All & 0.60 \\
$\sigma_{p f}$ & All & 0.20 & $\sigma_{m}$ & All & 0.20 \\
$\sigma_{p p}$ & All & 0.10 & $\sigma_{x}$ & 01,03 & 2.00 \\
$\sigma_{e}$ & $01-05$ & 0.10 & & 02 & 10.00 \\
& $06,07,12,13,14$ & 0.20 & & 05 & 0.50 \\
$\sigma_{e f}$ & Others & 0.40 & & $12,13,14,17$ & 0.10 \\
& $01-04$ & 0.10 & & 18 & 0.05 \\
& 05 & 1.50 & & Others & 3.00 \\
& 06-11 and 15-18 & 0.90 & $\sigma_{m m}$ & All & 0.20 \\
& Others & 0.30 & & & \\
\hline
\end{tabular}

as GDP or households' final consumption are not relevant indicators because they are calculated at constant prices, and thus ignore the welfare effects of a change in the structure of prices. The only consistent measure of welfare cost is households' surplus, which can be based either on the compensative variation of income $(C V I)$ or on the equivalent variation of income $(E V I)$. Though theoretically slightly different, they yield very close results as the change in the structure of prices is of a limited magnitude, and energy is a small share in average production cost of the economy and in households' budget. Deriving demand by households from a utility function then allows to have a direct economic measure of the welfare cost of abatement policies. Households' surplus may be directly reckoned from the numerical results of scenarios, for every year and every country/region, and they can be aggregated in various ways: either weighted by exchange rates and summed for a given year or period; or discounted through interest rates for a given country and then measuring the total discounted cost of the abatement policy. For a given period, households' surplus is representative of the total welfare gain if the other elements of final demand (except exports) are held constant. This is the case of the final demand of government, which is exogenous in the model as in most general equilibrium models. Concerning productive investment, which is endogenous in the model and is sensitive to changes in relative prices (and in particular to the change in the relative price of consumption and capital goods), surpluses calculated annually are representative of welfare cost if its total investment ${ }^{7}$ is constrained to be constant in the scenario. That is why such a constraint has effectively been retained in the model.

\subsection{Measuring surplus}

The economic cost of energy and environment policies can be measured comprehensively by changes in households' welfare since final demand of other

\footnotetext{
$\overline{7}$ But not of course, as noted before, its allocation between sectors.
} 
institutional sectors is supposed unchanged in scenarios. Measurement of this welfare change can be represented by the sum of the change in income and the CVI associated to the change in prices, according to the classical formula. In the case of a Stone-Geary utility function, the compensative variation for a change from an initial situation defined by the price system $\left(\overline{P C_{i r}}\right)$ to a final situation $\left(P C_{i r}\right)$ is such that:

$$
\frac{\overline{H C T}_{r}-\sum_{i} \overline{P C}_{i r} \cdot \phi_{i r}}{\Pi_{i}\left(\overline{P C}_{i r}\right)^{\beta_{i r}}}=\frac{\overline{H C T}_{r}+C V I_{r}-\sum_{i} P C_{i r} \cdot \phi_{i r}}{\Pi_{i}\left(P C_{i r}\right)^{\beta_{i r}}}
$$

The households' surplus is then:

$$
S_{r}=\left(H C T_{r}-\sum_{i} P C_{i r} \cdot \phi_{i r}\right)-\Pi_{i}\left(\frac{P C_{i r}}{\overline{P C}_{i r}}\right)^{\beta_{i r}}\left(\overline{H C T}_{r}-\sum_{i} \overline{P C}_{i r} \cdot \phi_{i r}\right)
$$

\subsection{Decomposition of surplus}

In a closed economy, households' surplus reflects the pure substitution effect of taxation, i.e. the deadweight loss of taxation ( $D W L)$. In an open economy, income effects are added to the pure substitution effect, and they are channeled through the change in the relative prices of foreign trade. Corresponding gains or losses from "terms of trade", as they are known in the specialized literature, may be an important and in some cases a dominant part of the total welfare gain or loss for a given country (though of course, they represent transfers and consolidate at the world level). $C V I$ and Terms of Trade $\left(G_{r}\right)$ can be reckoned directly from the numerical results of the model. $D W L$ is then obtained by subtracting the latter to the former, according to the following "Welfare Cost Algebra":

$$
\begin{gathered}
G_{r}=\sum_{i}\left(P X_{i r}-\overline{P X}_{i r}\right) \cdot \overline{E X}_{i r}-\sum_{i}\left(P I_{i r}-\overline{P I}_{i r}\right) \cdot \bar{M}_{i r} \\
D W L_{r}=S_{r}-G_{r}
\end{gathered}
$$

\subsection{Marginal abatement cost}

Definition of the marginal abatement cost may appear obvious, but its precise determination is more complex. According to the theoretical analysis, what is relevant for exchange in a market of tradable permits is the marginal abatement cost defined as the welfare loss at constant prices of foreign trade. On the other hand, this welfare loss is to be deflated by the social value of goods, since the permits is exchanged against tradable goods. Social values of goods differ from market prices of a quantity that is equal to marginal cost of public funds $\left(M C P F_{r}\right)$. Calculating marginal abatement cost at constant prices of foreign trade would normally require to operate separately for each country and for 
each period. However, it is possible to operate globally, and to eliminate the effects of change in the relative price of foreign trade by subtracting to marginal surplus the marginal gain or loss from terms of trade. In other terms, the marginal abatement cost is equal to the marginal deadweight loss of taxation deflated by $M C P F_{r}$ :

$$
M A C_{r}=\frac{1}{M C P F_{r}} \cdot \frac{\partial D W L_{r}}{\partial A_{r}}
$$

where $A_{r}$ represents the abatement in carbon.

As an example, we give the figures obtained for the year 2010 with the previous version of GEMINI-E3 that compares taxes and marginal abatement costs (see Figs. 5, 6). The major result is that for all four countries/regions considered the curve of marginal cost is above the curve of carbon price, with a distance that is relatively more important for France and Japan than for other European countries and the United States. A second observation is that, for high levels of abatement, the relative gap between the two curves tends to decrease. It may happen that the curve of marginal cost be situated below the curve of carbon price, which means in particular that the marginal abatement cost is negative (at least in the first stages of carbon abatement) then exhibiting a "doubledividend" phenomenon. The circumstances leading to a double-dividend are several, and there is in the literature a real competition for producing new cases. Two appear the most important and plausible: energy subsidization; distortions in markets and "rationing" due to price rigidity. Energy subsidization is clearly the situation prevailing in Russia and other ex-FSU countries, and results obtained with the model effectively show that, contrary to other Annex $\mathrm{B}$ countries, the curve of MAC is below the curve of carbon price. But as it appears in the Fig. 7, the gap is fairly small, and this may be explained by the low reliability of the statistical system, particularly concerning fiscal data.

\section{The new version GEMINI-EMU incorporating the single currency mechanisms}

In their vast majority-not to say their totality-world CGE models ignore the existence of monetary unions and in particular the most important one, the
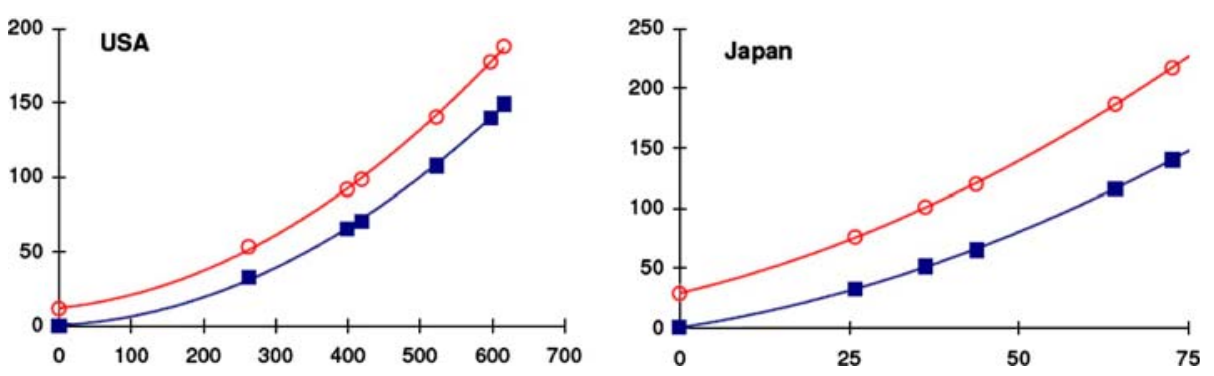

Fig. 5 Marginal abatement cost and tax for USA and Japan (in ECUs 1990 per t of C) 

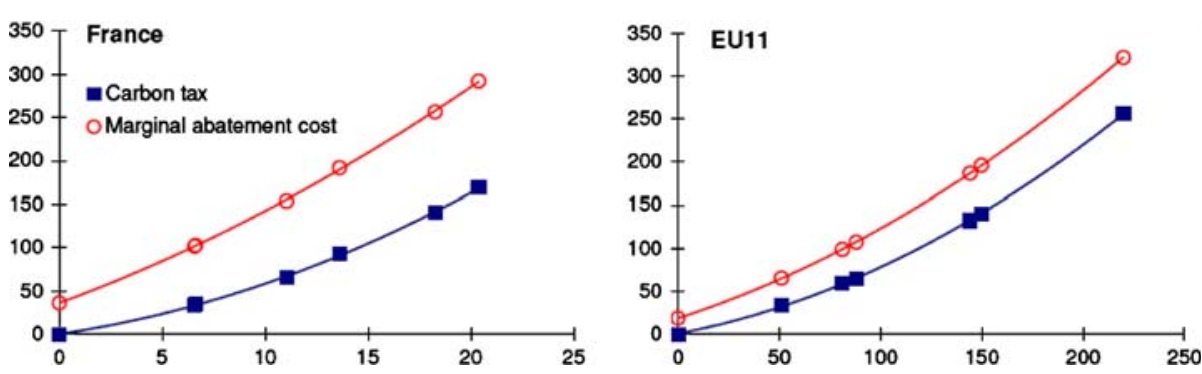

Fig. 6 Marginal abatement cost and tax for France and other European countries (in ECUs 1990 per $t$ of $\mathrm{C})$

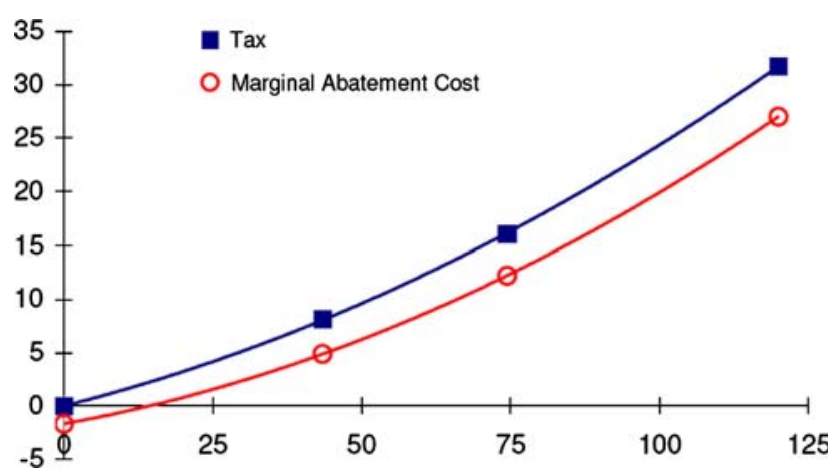

Fig. 7 Marginal abatement cost and tax for Former Soviet Union (in ECUs 1990 per $t$ of C)

European Monetary Union, established by the Maastricht Treaty and operative since January 1999 when the Euro was introduced. It is acknowledged that the existence of a monetary union affects trade, financial markets, macroeconomic policy making and Europe's economic performance and an important and growing literature is devoted to their appraisal, and in particular to the EMU. ${ }^{8}$

Representing the mechanisms and the constraints of a monetary union is not a simple task because by definition they are of "monetary" form and CGE models are essentially in real terms. The challenge is then to formulate-or "translate" - in real terms the monetary mechanisms of the EMU. The most prominent effect of the monetary union and of the use of a single currency across the EMU zone is of course the swing from a system of flexible exchanges rates to a system of fixed exchange rates. This is obvious in monetary terms but has to be transposed in real terms. Changes are also to be considered in the allocation of savings among member countries through the mobility of financial capital. And, at last, the constraints of the Euro become really binding at the macroeconomic level when flexibility in other markets - the labor market in particular-is not warranted.

\footnotetext{
8 See for instance (Baldwin et al. 2003; de Grauwe and Melitz 2005); and the numerous working papers in the website of the European Central Bank.
} 
A previous paper in French gives a comprehensive description of the new version of the model, and presents a large set of simulations related to the implementation of a "social VAT" in France (Bernard and Vielle 2006). A following paper in English focuses on similar policies possibly implemented in two other countries belonging to the EMU, Germany and Italy, according to the economic programs of the new Governments in charge and the declarations of their leaders. The presentation below of the structure and characteristics of GEMINI-EMU is taken from this paper.

\subsection{Exchange rates}

The underlying idea is to select a numéraire, i.e. a basket of goods, representing the Euro currency. More precisely, what is to be formulated is that the price of this numéraire remains constant across the member countries. The real exchange rates between them, calculated with this numéraire, are then fixed.

An obvious candidate for such a numéraire is a "common good" for these countries and it is then to be related to trade between them. The structure of intra-EMU foreign trade varies from one country to the other, and their average-weighted by the share of each country in trade-appears to be a relevant choice, which has been retained.

The exchange rate of the EMU with respect to other countries and regions is still considered as flexible, with the same balancing mechanism as mentioned above, under the constraint that total EMU foreign trade is balanced (or kept to a constant real deficit). Then, with a mechanism ensuring that total EMU foreign deficit is held constant, deficits or surpluses of member countries may diverge and can only be contained through the use of domestic macroeconomic and fiscal policies. But any decrease of deficit in one country has for counterpart an increase in at least one of the other member countries. There is, thus, spill-over effects between member countries channeled through the fixed exchange rates.

\subsection{Mobility of capital}

But beside stabilizing real exchange rates, the European Monetary Union unifies the money market and correlatively the financial markets. In real terms, this means that savings can be transferred from one country to the other without constraint, according to the expected profitability. In such an assumption of "perfect mobility of capital", equilibrium is reached when profitability is the same, i.e. when real interest rates (and costs of capital for the firms) are also equalized.

Perfect mobility of capital means that the market for commodities, at the aggregate level, is also unified with a single balancing constraint between investment and savings. In other terms, any demand for goods (investment goods in particular) that cannot be met in the domestic market is satisfied by imports from other EMU countries. Beside trade based on the above-described mechanism of imperfect competition a competitive trade but for a single commodity, obviously the Euro-numéraire, must be taken into account. 
The assumption of perfect mobility has also dramatic consequences on EMU-economies, with strong spill-over effects in particular in the case of a decrease of public deficit in a member country. Such a move-resulting either from a tax increase or a decrease of public consumption, leaves room for additional savings but the latter is shared between all member countries. The counterpart is an increase of trade surplus in the considered country and a decrease in other member countries.

Stability of real exchange rates and perfect mobility of capital set up for EMU member countries a totally different economic stage with strong spillover effects. Efficiency of macroeconomic-and in particular fiscal-policies cannot anymore be assessed with the same standards than in the case of flexible exchange rates and imperfect mobility of capital, which in some way insulates the domestic economy from the world environment, with re-equilibrating and compensating mechanisms through the change in the terms of trade.

Spill-over effects imply that uncoordinated macroeconomic policies in member countries can lead to inefficient equilibria, because no country has an incentive to take them into account. This is not a new idea: as early as in the beginning of the sixties, Richard Mundell warned on the effects of uncoordinated domestic macroeconomic policies within a monetary union and stressed the need for fiscal cooperation, if not harmonization. The various simulations performed with the model, and the results presented in the next section, highlight these two statements.

\subsection{Balancing in the labor market}

Most-if not all-CGE models assume competitive equilibria in all domestic markets, including the labor market. The reason is that these models, in particular when applied to energy and environment issues, focus on the medium to long run effects, and such an assumption may be considered as likely for such an horizon (at least for developed countries), or at least a standard or a benchmark.

When applied to macroeconomic and fiscal policy, or to sectoral issues on a short to medium run, the representation of the labor market has to be consistent with what is observed, i.e. a persistent unemployment. This is the case of European countries, and particularly member countries of EMU. The main three of them, Germany, France and Italy, have unemployment rates of over or close to $10 \%$. Unemployment has several origins and a comprehensive survey should analyze and measure the importance of each of them. In the framework of a simulation model, we have to consider the one which appears the most important, and the most difficult to alleviate. Beside structural and frictional unemployments, the modern economic theory distinguishes two types, Keynesian and classical (or neo-classical) unemployments. ${ }^{9}$

\footnotetext{
9 Another possible cause for unemployment is imperfect competition between firms, whose supply of goods and demand for labor are smaller than in the competitive setting (see Malinvaud 1988).
} 
Keynesian unemployment is the result of unbalance in the markets of goods (at least one of them), due to the stickiness of prices. Classical unemployment is the unbalance in the labor market, due to the stickiness of wages. Formation of wages, obeying to some indexation mechanism rather than the correction of the gap between supply and demand of labor, results in a situation of rationing of the former by the latter. If Keynesian unemployment is likely in a closed economy, it is not credible in an open economy and world markets. Demand for goods is "unlimited", and what limits the supply by firms is their competitiveness, i.e. the level of output that is profitable at the given market prices. And this is the representation retained in the model.

Under such a representation, an important assumption is linked to the indexation mechanism of wages. Several indexes may be and will be considered in the analysis, the money, the price of GDP and the price of consumption. Monetary indexation means that wages in real money (the numéraire representing the Euro) are held constant. The two other rules index the wages on the numéraires representing the GDP or the households' final consumption. The latter is the consumer price index, as it can be measured in the model.

It is important to note that, as the model is applied only for simulation purposes, the indexation rules must be understood in "variation". Over time, and notably in the reference scenario, other mechanisms may or are effectively taken into account. What the above rules mean is that, when a given policy changes the price system, wages are supposed to be increased in the same proportion as the considered index.

Wages indexation plays an important role because it commands the competitiveness of the considered economy. For instance an increase of the VAT has very different effects with an indexation of wages on the CPI than with a nominal indexation (indexation on the GDP price being intermediate).

\subsection{A modeling with three numéraires}

A special feature of the model is the simultaneous use of three numéraires. The first one is purely "technical", and is only used to normalize the price system in each country, in each year. Prices of all goods are defined respectively to this numéraire, set equal to one (without loss of generality). Any good can be taken as numééraire, but it is convenient-and usual, particularly in the theory of taxation, to select labor. All prices are then deflated by wages (prices in "purchasing power" of labor). Price systems of each country in each year are connected together through the real exchange rates and the real interest rates.

The second numéraire represents the common currency of the EMU, i. e. the Euro, and is based on the average structure of the intra-EMU trade.

The third numéraire is the reference for wages indexation, either the previous one (nominal indexation) or one of the two price indexes, GDP implicit price or consumer price index (CPI). It can be noted that the selection of labor as "technical" numéraire does not prevent to impose a constraint on wages. Effectively the constraint is on wages deflated by the numéraire of indexation. 
As wages are put equal to one, the constraint is effectively on the numéraire of indexation. This is how the model works, but it does not impose any undue constraint on the representation of the economy.

\section{Conclusion}

Computable General Equilibrium models have a main virtue, which is total consistency both at the domestic and at the world levels, and are then very demanding: any error or approximation is deadly because it is not possible to resolve a square model (same number of variables and equations) if the equations are not compatible.

But - and this is the lesson that can be drawn from our long experience with GEMINI-E3 - CGE models are very flexible. First of all in their nomenclatures, with the obvious acknowledgment that a precise assessment of detailed policies may require to increase the number of sectors and/or countries/regions. In our case, we started with three countries/regions and eight sectors and now we are respectively at the figures of 28 and 18 .

This is also the case for the specification of the model and the economic mechanisms to be taken into account in order to simulate the effective conditions and working of each economy and the relations between them, through the various channels. Though the initial paradigm of CGE models was full flexibility in all markets, more and more either stickiness or unbalances - in the sense of rationing of demand by supply or vice versa - or institutional constraints - such as the existence of a monetary union - have to be coped with in order to obtain a relevant measure of the effects of contemplated policies. CGE models thus differ significantly from sectoral models because they take into account the indirect effects of policies, through the re-balancing of all markets - whether they are perfectly competitive or not-and the closing of the economic circuit.

These indirect effects are at the heart of what is known-and frequently evoked in the literature - under the term of "double-dividend". It is of course licit to assert that a given policy - and this is very usual in the case of climate change policies - has a double-dividend but we must explain what are precisely its source and consistence, and check that its sign is effectively positive, not negative.

Acknowledgements Partly supported by TOCSIN (EU-044287).

\section{A Appendix: Variable and parameter dictionary}

A.1 Index

$i, k \quad: \quad$ Sector or product

$r, h$ : Region

$t$ : Time

$l \quad: \quad$ Type of non carbon greenhouse gas emissions 


\section{A.2 Variables}

\section{Quantity}

$M A_{i r} \quad$ : Material consumption in sector $i$ in region $r$

$M R_{\text {irh }} \quad$ : Imports in product $i$ by region $r$ coming from region $h$

$N C O 2_{l r}$ : non carbon greenhouse gas emissions in source $l$ in region $r$

$O T R_{i r} \quad: \quad$ Other material inputs consumption (i.e. material input minus $T R_{i r}$ ) by sector $i$ in region $r$

$T R_{i r} \quad: \quad$ Transport services consumption by sector $i$ in region $r$

$Y_{i r} \quad: \quad$ Total demand in product $i$ in region $r$

$X_{i r} \quad$ : Domestic production for sector $\mathrm{i}=5, \ldots, 18$, standard inputs consumption for sector $\mathrm{i}=1, \ldots, 4$

$X A_{i r} \quad: \quad$ Anticipated domestic production in sector $i$ in region $r$

$X P F_{i r} \quad: \quad$ Domestic production in fossil fuel product $i$ in region $r$

$X_{4 P} \quad$ : Domestic production in refined products in region $r$

\section{Price}

$e_{r} \quad:$ Exchange rate of region $r$

$M A C_{r} \quad$ : Marginal cost of carbon abatement in region $r$

$M_{P F P}$ : Marginal cost of public funds in region $r$

$P B_{i r} \quad: \quad$ Base price of product $i$ in region $r$

$P C_{i r} \quad$ : Price of household consumption for product $i$ in region $r$

$P D_{i r} \quad$ : Price of domestic production (sector $\left.\mathrm{i}=5, \ldots, 18\right)$ price of standard inputs consumption (sector $\mathrm{i}=1, \ldots, 4)$

$P D A_{i r} \quad: \quad$ Anticipated price of domestic production in sector $i$ in region $r$

$P D F_{i r} \quad: \quad$ Price of fossil fuel product $i$ in region $r$

$P D P_{4 r} \quad$ : Price of petroleum products in region $r$

$P E_{i r} \quad$ : Price of energy in sector $i$ in region $r$

$P E F_{\text {ir }} \quad$ : Price of fossil fuel consumption in sector $i$ in region $r$

$P F_{i r} \quad: \quad$ Price of fixed factor in sector $i$ in region $r$

$P G_{i r} \quad$ : Price of government consumption for product $i$ in region $r$

$P I_{i r} \quad:$ Import price of product $i$ in region $r$

$P I C_{k i r} \quad$ : Price of intermediate consumption in product $k$ by sector $i$ in region $r$

$P K_{i r} \quad: \quad$ Rental price of capital in sector $i$ in region $r$

$P L_{i r} \quad$ : Labor price in sector $i$ in region $r$

$P M_{i r} \quad$ : Price of material consumption in sector $i$ in region $r$

$P O T R_{i r} \quad$ : Price of other material inputs (i.e. material input minus $T R_{i r}$ ) in sector $i$ in region $r$

$P T R_{i r} \quad: \quad$ Price of transport services inputs in sector $i$ in region $r$

$P V_{i r} \quad: \quad$ Price of investment product $i$ in region $r$

$P V A_{i r} \quad: \quad$ Anticipated price of investment product $i$ in region $r$

$P X_{i r} \quad: \quad$ Export price of product $i$ in region $r$

$P Y_{i r} \quad: \quad$ Price of product $i$ in region $r$

$R_{r} \quad:$ Interest rate in region $r$

$\mathrm{TCO}_{r}$ : Carbon price in region $r$

$W_{r} \quad$ : Wage in region $r$ 
Value

$H C T_{r}$ : Total consumption in region $r$

$S B_{r} \quad:$ Social benefit in region $r$

$S G_{r} \quad$ : Government saving in region $r$

$\mathrm{SH}_{r} \quad$ : Household saving in region $r$

$R_{r} \quad$ : Household revenue in region $r$

\section{A.3 Parameter}

\section{Taxation}

$\kappa_{i r}^{b} \quad: \quad$ Indirect taxes rate of sector $i$ in region $r$

$\kappa_{i r}^{e} \quad$ : Excises tax rate on household consumption of product $i$ in region $r$

$\kappa_{i r}^{g} \quad$ : Tax rate on government consumption of product $i$ in region $r$

$\kappa_{i r}^{h} \quad$ : Tax rate on household consumption of product $i$ in region $r$

$\kappa_{i r}^{i} \quad: \quad$ Duty rate on product $i$ in region $r$

$\kappa_{r}^{r} \quad$ : Direct tax rate in region $r$

$\kappa_{k i r}^{v} \quad: \quad$ Tax rate on investment of product $k$ of sector $i$ in region $r$

$\kappa_{i r}^{w} \quad$ : Tax rate on wages of sector $i$ in region $r$

$\kappa_{i r}^{k} \quad$ : Tax rate on capital income of sector $i$ in region $r$

$\kappa_{i r}^{x} \quad$ : Tax rate on exports of sector $i$ in region $r$

$\kappa_{i r}^{c} \quad$ : Tax rate on base price of sector $i$ in region $r$ due to non carbon greenhouse gas emissions

\section{Coefficient}

$\phi_{\text {ir }} \quad$ : Parameter of household consumption: minimum necessary purchase

$\beta_{\text {ir }} \quad$ : Parameter of household consumption: marginal budget share

$\beta_{i r}^{g} \quad:$ Share parameter of government consumption

$\Phi_{i k r}$ : Transfer matrix between investment by sector and investment by product

$\tau_{i r}^{h} \quad$ : Carbon content of one unit of household consumption in product $i$

$\tau_{i r}^{g} \quad$ : Carbon content of one unit of government consumption in product $i$

$\tau_{i k r}^{i} \quad$ : Carbon content of one unit of intermediate consumption in product $i$ by sector $k$

$\chi_{i r}:$ Adjustment factor

$\zeta_{r} \quad: \quad$ Rate of household savings

$\varepsilon_{r} \quad:$ Government saving

$\lambda_{i r}^{x} \quad$ : Scale parameter of $C E S\left(M_{i r}\right.$, Domestic production)

$\lambda_{i r} \quad$ : Scale parameter of $C E S\left(K_{i r}, L_{i r}, E_{i r}, M A_{i r}\right)$

$\lambda_{i r}^{i} \quad$ : Scale parameter of $C E S\left(M R_{i r 1}, \ldots, M R_{i r 28}\right)$

$\lambda_{i r}^{p f}:$ Scale parameter of $C E S\left(F F_{i r}, X_{i r}\right)$

$\lambda_{4 r}^{p p}:$ : Scale parameter of CES $\left(I C_{24 r}, X_{4 r}\right)$

$\lambda_{i r}^{e} \quad:$ Scale parameter of $C E S\left(I C_{5 i r}, E F_{i r}\right)$

$\lambda_{i r}^{e f} \quad: \quad$ Scale parameter of $C E S\left(I C_{1 i r}, I C_{3 i r}, I C_{4 i r}\right)$

$\lambda_{i r}^{m m} \quad: \quad$ Scale parameter of $C E S\left(T R_{i r}, O T R_{i r}\right)$ 


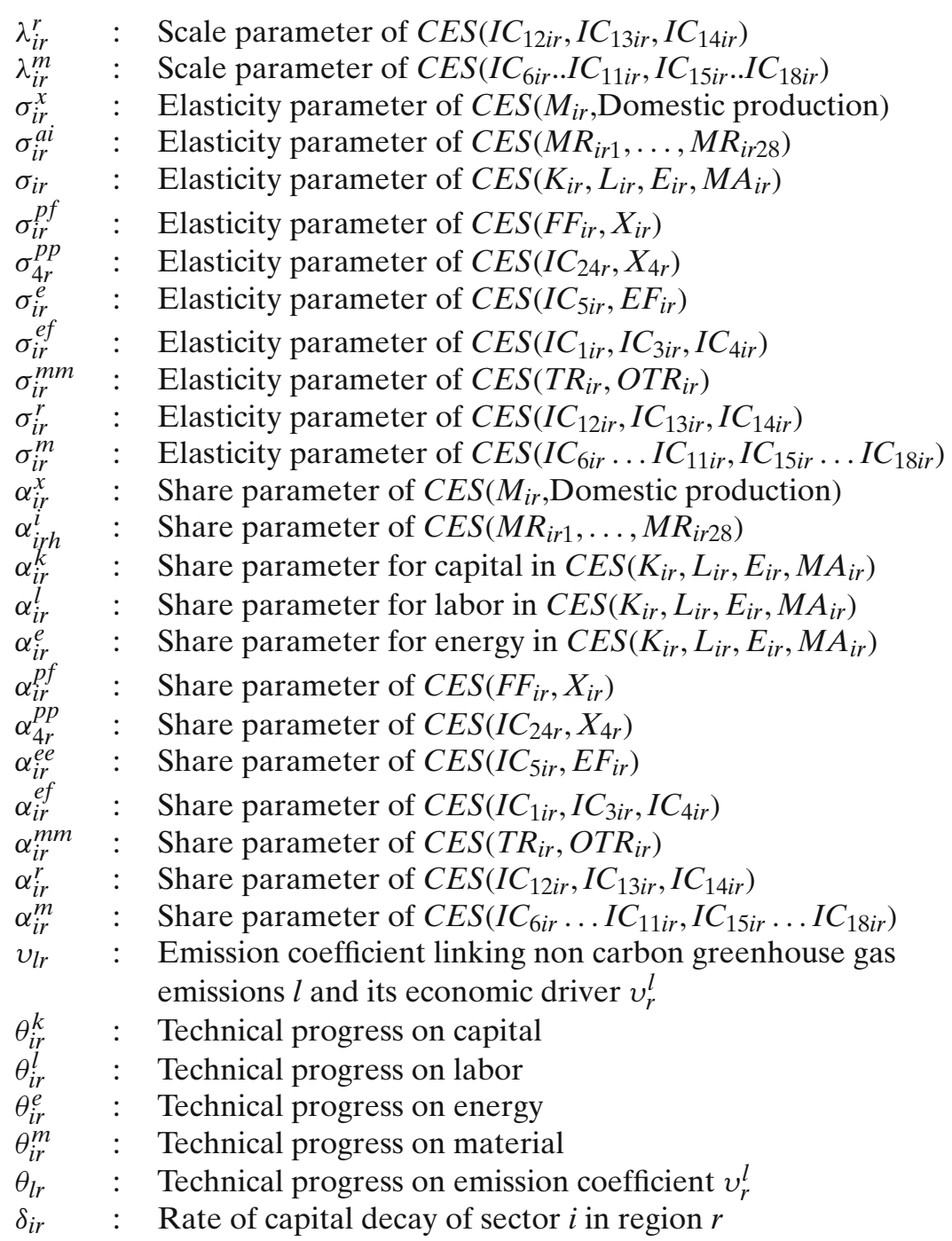

\section{References}

Armington PS (1969) A theory of demand for products distinguished by place of production. IMF Staff Papers 16:159-78

Baldwin R, Bertola G, Seabright P (2003) EMU: assessing the impact of the euro, special issue of economic policy. Blackwell, Oxford

Bernard A, Vielle M (1998) La structure du modèle GEMINI-E3. Econ Prévis 5(136)

Bernard A, Vielle M (1999a) Report to French Inter Ministerial Task Forces on Climate Change: Evaluations of the Kyoto Protocol with GEMINI-E3. Technical report

Bernard A, Vielle M (1999b) Report to French Inter Ministerial Task Forces on Climate Change: Industrial Evaluations of the Kyoto Protocol with GEMINI-E3. Technical report

Bernard A, Vielle M(2000a) An appraisal of the French Nuclear Program with Respect to the Kyoto Protocol through a World, Dynamic, General Equilibrium Model (working paper) 
Bernard A, Vielle M (2000b) Comment allouer un coût global d'environnement entre pays: permis négociables versus taxes ou permis négociables et taxes? Econ Int (82):103-135

Bernard A, Vielle M (2002) Does Non Ratification of the Kyoto Protocol by the US Increase the Likelihood of Monopolistic Behavior by Russia in the Market of Tradable Permits? (working paper)

Bernard A, Vielle M (2003) Measuring the welfare cost of climate change policies: a comparative assessment based on the computable general equilibrium model GEMINI-E3. Environ Model Assess 8(3):199-217

Bernard A, Vielle M (2006) New Framework for Assessing Macroeconomic and Sectoral Policies Within the European Monetary Union - Application to the German and Italian Fiscal Policies. working paper CGPC/CEA

Bernard A, Paltsev S, Reilly JM, Vielle M, Viguier L (2003) Russia's Role in the kyoto protocol. Report 98, MIT Joint Program on the Science and Policy of Global Change, Cambridge

Bernard A, Vielle M, Viguier L (2004) Climate Policy, Distortionary Taxation, and the Double Dividend Hypothesis: A General Equilibrium Analysis of the Swiss Case. Working Paper, NCCR-WP4, Geneva

Bernard A, Vielle M, Viguier L (2005a) Carbon tax and international emissions trading: a swiss perspective. In: Haurie A, Viguier L (eds) The Couplings of Climate and Economic Dynamics. Advances in Global Change Research, vol 22 Kluwer, Dordrecht pp 295-319

Bernard A, Vielle M, Viguier L (2005b) Premières simulations de la directive européenne sur les quotas d'mission avec le modle GEMINI-E3. Econ Prévis 3/4/5(169-170-171):171-196

Bernard A, Talbi B, Vielle M (2006a) GEMINI-E3 Tunisie: Un outil d'aide à la prospective énergétique. Working Paper, French Ministry of Equipment Transport and Housing, LERNA, Laboratoire dEconomie et de Gestion Industrielle de Tunis

Bernard A, Vielle M, Viguier L (2006) Burden sharing within a multi-gas strategy. Energy J, Multigas Mitigation and Climate Policy, Special Issue \#3:289-304

de Grauwe P, Melitz J (2005) In: de Grauwe P, Melitz J (eds) Prospects for monetary unions after the euro, CESIfo Seminar Series. MIT Press

DeAngelo BJ, de la Chesnaye FC, Beach RH, Sommer A, Murray BC (2006) Methane and nitrous oxide mitigation in agriculture. Energy J, Multi-Greenhouse Gas Mitigation and Climate Policy, Special Issue \#3:89-108

Delhotal KC, de la Chesnaye FC, Gardiner A, Bates J, Sankovski A (2006) Mitigation of methane and nitrous oxide emissions from waste, energy and industry. Energy J, Multi-Greenhouse Gas Mitigation and Climate Policy, Special Issue \#3:45-62

Dimaranan BV (2006) Global trade, assistance, and production: the GTAP 6 data base. Center for Global Trade Analysis, Purdue University (in press)

Ferris MC, Munson TS (2000) Complementarity Problems in GAMS and the PATH Solver. J Econ Dyn Control 24:165-188

Ferris MC, Pang JS (1997) Complementarity and variational problems: state of the art. SIAM Publications, Philadelphia

Houghton JT, Meira Filho LG, Lim B, Treanton K, Mamaty I, Bonduki Y (1997) Revised 1996 IPCC Guidelines for National Greenhouse Gas Inventories. Intergovernmental Panel on Climate Change, Organization for Economic Co-Operation and Development, International Energy Agency. UK Meteorological Office, Bracknell

International Energy Agency (2002a) Energy Balances for non-OECD Countries. OECD/IEA, Paris

International Energy Agency (2002b) Energy Balances for OECD Countries. OECD/IEA, Paris

International Energy Agency (2005) Energy prices \& taxes. OECD/IEA, Paris, fourth quarter Quartely Statitics

International Monetary Fund (2004) Government Finance Statistics. IMF, Washington, D.C. 20431, USA

Malinvaud E (1998) Les cotisations sociales à la charge des employeurs: analyse économique. Les rapports du Conseil d'Analyse Economique. La Documentation Française

Organisation For Economic Co-operation and Development (2003) Revenue Statistics 1965-2002. OECD, Paris

Organisation For Economic Co-operation and Development (2005) National Accounts for OECD Countries. OECD, Paris 
Reinert KA, Roland-Holst DW (1997) Social accounting matrices. In: Francois JF, Reinert KA (eds) Applied methods for trade policy analysis, chap. 4. Cambridge University Press, New York pp. $94-121$

Schaefer DO, Godwin D, Harnisch J (2006) Estimating future emissions and potential reductions of HFCs, PFCs, and SF6. Energy J, Multi-Greenhouse Gas Mitigation and Climate Policy, Special Issue \#3:63-88

Scheehle EA, Kruger D (2006) Global anthropogenic methane and nitrous oxide emissions. Energy J, Multi-Greenhouse Gas Mitigation and Climate Policy, Special Issue \#3:33-44

Stone JRN (1983) Linear expenditure systems and demand analysis: an application to the pattern of British demand. Econ J 64:511-527

United Nations Department of Economic and Social Affairs, Population Division 191 (2006) World Population Prospects: The 2004 Revision, Volume III Analytical Report. United Nations, New York

United States Environmental Protection Agency (2006) Global Mitigation of Non-CO2 Greenhouse Gases. Office of Atmospheric Programs (6207J) EPA 430-R-06-005, Washington, DC 20460

Vielle M, Viguier L (2007) On the climate change effects of high oil prices. Energy Policy 35(2): 844-849

Van Vuuren D, Weyant JP, de la Chesnaye F (2006) Multi-gas scenarios to stabilize radiative forcing. Energy Econ 28(1):102-120

Weyant J, de la Chesnaye F, Blanford G (2006) Overview of EMF-21: multigas mitigation and climate policy. Energy J, Multi-Greenhouse Gas Mitigation and Climate Policy, Special Issue \#3:1-32 